\title{
Composition, polyphenol bioavailability, and health benefits of aronia berry: a review
}

\author{
Erica S. King and Bradley W. Bolling $\mathrm{a}^{\mathrm{a}}$
}

\begin{abstract}
aDepartment of Food Science, University of Wisconsin-Madison, 1605 Linden Dr., Madison, WI 53706, USA
* Corresponding author: Bradley W Bolling, Department of Food Science, University of Wisconsin-Madison, 1605 Linden Dr. Madison, WI 53706, USA. Tel: 608-890-0212; E-mail: bwbolling@wisc.edu
\end{abstract}

DOI: $10.31665 /$ JFB. 2020.11235

Received: July 04, 2020; Revised received \& accepted: September 11, 2020

Citation: King, E.S., and Bolling, B.W. (2020). Composition, polyphenol bioavailability, and health benefits of aronia berry: a review. J. Food Bioact. 11: 13-30.

\begin{abstract}
Aronia berries (Aronia melanocarpa and Aronia mitschurinii) are underutilized functional food, rich in bioactives. Aronia berries have abundant levels of anthocyanins, proanthocyanidins, flavonols, and phenolic acids that may reduce the risk of non-communicable diseases such as diabetes, metabolic syndrome, and neurological disease. Aronia polyphenols are bioavailable, and the majority are transformed into low molecular-weight phenolics. The impact of biotransformation on aronia polyphenols health effects is not fully understood. The objective of this review is to analyze aronia berry composition, including polyphenols nutrients. Additionally, this review summarizes recent preclinical and clinical studies on the polyphenol bioavailability and health benefits upon aronia berry consumption to better understand its potential as a functional food.
\end{abstract}

Keywords: Aronia berry; Anthocyanin; Chronic disease; Composition; Polyphenol.

\section{Introduction}

Aronia Medik. (chokeberries), are deciduous shrubs and a member of the Rosaceae family (Sidor and Gramza-Michałowska, 2019; Mahoney et al., 2019). Aronia berry color ranges from red, purple, to black, depending on the species (Sidor and GramzaMichałowska, 2019). The four main Aronia species include $A$. arbutifolia (L.), A. melanocarpa (Michx.), A. prunifolia (Marshall), and $A$. mitschurinii (Mahoney et al., 2019; Kulling and Rawel, 2008). A. mitschurinii is the primary species used for commercial aronia berry production in North America (Brand et al., 2017; Mahoney et al., 2019). The 'Nero' and 'Viking' cultivars of A. mitschurinii are crosses between A. melanocarpa and Sorbus aucuparia L. and grow from 3 to 6 feet tall (Mahoney et al., 2019; Kulling and Rawel, 2008). From May to June, white flowers grow on the shrubs, and by late August and September, the berries are fully matured, with a diameter between 6.1 to $17.8 \mathrm{~mm}$ (Kulling and Rawel, 2008).

Aronia berry is consumed as whole berries, but most of the crop is processed to juice, juice concentrates, extracts, fruit powders, jams, or fermented products. Aronia berry is rich in polyphenols, which may contribute to its health benefits. Aronia berries contain a mixture of polyphenolic components and have abundant anthocyanins and proanthocyanidins (Taheri et al., 2013). Although the in vivo bioactivity and bioavailability of polyphenols are not fully understood, the antioxidant and antiinflammatory actions of polyphenols may decrease the risk of cardiovascular disease, metabolic syndrome, inflammation, and neurodegenerative disease (Jakobek and Seruga, 2012; Bhaswant et al., 2017). The mechanisms by which anthocyanins, proanthocyanidins, and other polyphenols found in aronia berries are an active reseach area.

Aronia berry remains an underutilized functional food. Prior reviews have addressed aronia berry composition (Sidor and Gramza-Michałowska, 2019), polyphenol bioavailability (Denev, Kratchanov, Ciz, Lojek, and Kratchanova, 2012), and health benefits (Sidor and Gramza-Michałowska, 2019). Additional reports on the composition, polyphenol bioavailability, and bioactive mechanisms have been published since these publications. Therefore, this paper aims to provide an updated and expanded review of the 
Table 1. Aronia berry and juice sugar content and profile

\begin{tabular}{cll}
\hline Sugar & Mass in fruit $(\mathrm{g} / 100 \mathrm{~g} \mathrm{fwb})$ & Mass in juice $(\mathrm{g} / \mathbf{1 0 0 \mathrm { mL }})$ \\
\hline total sugars & $6.21-42.10^{\mathrm{a}, \mathrm{g}}$ & $8.9-19.6^{\mathrm{e}, \mathrm{f}}$ \\
fructose & $2.2-15.8^{\mathrm{b}}$ & $1.5-4.1^{\mathrm{e}, \mathrm{f}}$ \\
glucose & $1.09-5.7^{\mathrm{c}, \mathrm{d}}$ & $1.5-4.2^{\mathrm{e}, \mathrm{f}}$ \\
sorbitol & $4.36-12.99^{\mathrm{c}, \mathrm{b}}$ & $3.5-7.7^{\mathrm{e}}$ \\
sucrose & $0.07-1.53^{\mathrm{b}, \mathrm{d}}$ & $0.03-6.8^{\mathrm{e}, \mathrm{f}}$ \\
inositol & $0.0684^{\mathrm{g}}$ & $-^{+}$ \\
maltose & $0.0496^{\mathrm{g}}$ & - \\
glycerol & $0.00983^{\mathrm{g}}$ & - \\
\hline
\end{tabular}

Abbreviations: fwb, fresh weight basis. ${ }^{\dagger}$ Data not available in literature. a Ochmian et al., 2012. bDenev et al., 2018. 'Mayer-Miebach et al., 2012. dŠnebergrová et al., 2014. eSosnowska et al., 2015. fHandeland et al. 2014. ' VVázquez-Espinosa et al. 2019.

current scientific literature on aronia berry composition, the pharmacokinetics of the polyphenols, and its potential for improving health. We expect that characterizing the progress and knowledge gaps in these areas will accelerate research, development, and aronia berry utilization.

\section{Methods}

Publications were identified through Medline, Elsevier, Google Scholar, and Pubmed databases using keywords such as aronia, antioxidants, anthocyanins, bioavailability, chokeberry, proanthocyanidins, cancer, cardiovascular disease, diabetes, functional foods, and polyphenols. Studies were limited from 2010 until 2020 and from 2015 for preclinical and human intervention studies. Compositional data were compiled for black aronia berry (A. melanocarpa and A. mitschurinii).

\section{Aronia composition}

The functional components in aronia berry include nutrients, polyphenols, fiber, and sorbitol. Other components such as organic acids, protein, and lipids contribute to fruit quality and stability. The abundance and distribution of these components vary significantly among the studies reviewed in this paper. Variability may arise from aronia genetic variability, environment (location, humidity, temperature, rain, fertilizers, and infections), harvest time, and other factors (Veberic et al., 2015). Furthermore, analysis may further introduce variability from extraction methods (e.g. selection of solvent, berry particle sizes, solid-solvent ratio, time, and temperature) or analytical approach (e.g. HPLC vs. gas chromatography, specific or non-specific methods) (Denev et al., 2018).

\subsection{Carbohydrates}

Aronia berry carbohydrates are primarily sugars and fiber (Tables 1 and 2). Fresh aronia berry contains 15 to $20.9 \mathrm{~g} / 100 \mathrm{~g}$ fwb of carbohydrates (Sidor and Gramza-Michałowska, 2019). The sugars in aronia berry and juice are mainly fructose and sorbitol with lower amounts of glucose and sucrose, ranging from 6.2 to $20.9 \mathrm{~g} / 100 \mathrm{~g}$ fwb or 8.9 to $19.6 \mathrm{~g} / 100 \mathrm{~mL}$. Sorbitol is abundant in aronia berry with $4.36-12.99 \mathrm{~g} / 100 \mathrm{~g}$ fwb of the whole berry. As a sugar alcohol, sorbitol contains about 2.6 calories per gram and has diuretic, laxative, and cathartic properties (US Food and Drug Administration, 2020; Featherstone, 2015). A majority of the berry sugars are extracted into juice, whereas its fiber is mainly distributed in the pomace. The pomace contains 57.8 to 71.5 $\mathrm{g} / 100 \mathrm{~g} \mathrm{dwb}$ of total dietary fiber and insoluble fiber at 43.8 to $61.7 \mathrm{~g} / 100 \mathrm{~g} \mathrm{dwb}$ (Schmid et al., 2020). The berry pomace fibers include cellulose (34 g/100 g dwb), hemicellulose (32 g/100 g $\mathrm{dwb})$, lignin (22.7 g/100 g dwb), and pectin (7.52 g/100 g dwb). Although these fibers' structures and solubility vary, increased fiber reduces cardiovascular disease risk, aids in glycemic control, and helps maintain a healthy weight (Schmid et al., 2020;

Table 2. Aronia berry pomace fiber content

\begin{tabular}{ll}
\hline Fiber & Mass in pomace (g/100 g dwb) \\
\hline total fiber & $57.8-71.6^{\mathrm{a}}$ \\
insoluble fiber & $43.8-61.7^{\mathrm{a}}$ \\
soluble fiber (high molecular weight) & $7.3-15.1^{\mathrm{a}}$ \\
soluble fiber (low molecular weight) & $0.8-2.6^{\mathrm{a}}$ \\
lignin & $22.68^{\mathrm{b}}$ \\
cellulose & $34.56^{\mathrm{b}}$ \\
total pectin & $7.52^{\mathrm{b}}$ \\
hemicellulose & $32.08^{\mathrm{b}}$ \\
\hline
\end{tabular}




Table 3. Protein content and amino acid profile of aronia berry and pomace

\begin{tabular}{|c|c|c|}
\hline Protein or amino acid & Mass in fruit (mg/100 $\mathrm{g} \mathrm{fwb)}$ & Pomace (mg/100 g dwb) \\
\hline total protein & $700^{\mathrm{a}}$ & $4,900-24,000^{b}$ \\
\hline aspartic acid (mg) & $0.01-0.035^{c}$ & $0.891^{d}$ \\
\hline glutamic acid (mg) & $0.04-0.029^{c}$ & $1.979^{d}$ \\
\hline serine (mg) & $0.023-0.039^{c}$ & $0.368^{d}$ \\
\hline histidine (mg) & $0.007-0.008^{c}$ & $0.247^{d}$ \\
\hline glycine (mg) & $0.009-0.018^{c}$ & $0.638^{d}$ \\
\hline threonine (mg) & $0.033-0.039^{c}$ & $0.298^{d}$ \\
\hline arginine (mg) & $0.01-0.013^{c}$ & $0.791^{d}$ \\
\hline alanine (mg) & $0.015-0.022^{c}$ & $0.41^{d}$ \\
\hline tyrosine (mg) & $0.003-0.006^{c}$ & $0.247^{d}$ \\
\hline valine (mg) & $0.021-0.025^{c}$ & $0.421^{d}$ \\
\hline methionine (mg) & ND- $-0.001^{c}$ & $0.177^{d}$ \\
\hline phenylalanine (mg) & $0.004-0.006^{c}$ & $0.43^{d}$ \\
\hline isoleucine (mg) & $0.008-0.012^{c}$ & $0.378^{d}$ \\
\hline leucine (mg) & $0.007-0.01^{c}$ & $0.686^{d}$ \\
\hline
\end{tabular}

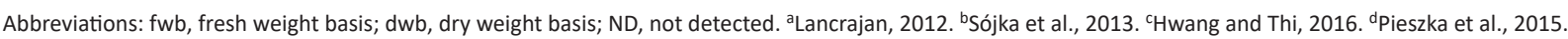

Slavin, 2013).

\subsection{Protein and amino acids}

Similar to other berries, the protein and amino acid content of aronia berry is relatively low (Table 3), $700 \mathrm{mg} / 100 \mathrm{~g}$ fwb and 4,900 to $24,000 \mathrm{mg} / 100 \mathrm{dwb}$. Most of the protein and amino acids are distributed in the pomace (Sidor and Gramza-Michałowska, 2019). Aronia berry contains both essential and nonessential amino acids. Threonine ( 0.033 to $0.39 \mathrm{mg} / 100 \mathrm{~g}$ fwb berry) is the most abundant among the amino acids, followed by serine $(0.023$ to 0.39 $\mathrm{mg} / 100 \mathrm{~g}$ fwb berry).

\subsection{Lipids}

Aronia berry has a low lipid content, with a total fat of $0.14 \%$ in a fresh berry (Table 4). A significant amount of the lipids are in the seed oil, represented mostly by sterols and phospholipids (Sidor and Gramza-Michałowska, 2019). The remaining lipids are mainly in the pomace, primarily polyunsaturated fatty acids, which is $90.49 \%$ of total fatty acids, whereas saturated fatty acid is $9.51 \%$. Among the different types of fatty acids, the linoleic (C18:2) and oleic acids (C18:1) are abundant, at $43.43 \%$ and $16.38 \%$ of fatty acids, respectively (Sidor and Gramza-Michałowska, 2019). While the lipid content of aronia berry is low, processing strategies to recover lipids from aronia seeds and pomace could be used to develop new sources of seed oils with high proportions of unsaturated fatty acids.

\subsection{Vitamins and minerals}

Aronia berry contains vitamin A, vitamin E, and vitamin C (Table 5). Total carotenoids (including $\alpha$-, $\beta$-, and $\zeta$-carotenes) can be up to $97.8 \mu \mathrm{g} / \mathrm{L}$ of aronia berry juice (Oprea et al., 2014; Sidor and Gramza-Michałowska, 2019). However, vitamin C is the most abundant micronutrient, with 7.25 to $98.75 \mathrm{mg} / 100 \mathrm{~g}$ fwb (Catană et al., 2017). Aronia berries also contain a variety of minerals. The ash content of aronia berry is 0.37 to $0.49 \mathrm{~g} / 100 \mathrm{~g}$ fwb, providing major minerals (calcium, magnesium, phosphorus, potassium) and trace minerals (iron, copper, iodine, zinc, and selenium) (MedlinePlus, 2019). Lead and other heavy metals have been reported in aronia berry, but these levels are below thresholds where toxicity is a concern (Juranović Cindrić et al., 2017).

\subsection{Organic acids}

The content of organic acids in aronia leads to its sour flavor (Famiani et al., 2015). The titratable acidity is in range with other berries at 0.85 to $1.22 \%$ (Bolling et al., 2015). At least eight organic acids are present in aronia berry, including quinic, malic, ascorbic, shikimic, citric, oxalic, succinic, and isocitric acids (Table 6). Fumaric and tartaric acids were also reported in juice. Quinic acid is the most abundant organic acid in aronia berry ( 293 to $591 \mathrm{mg} / 100 \mathrm{~g}$ fwb), followed by malic acid (308 to 350 $\mathrm{mg} / 100 \mathrm{~g} \mathrm{fwb}$ ), but others have reported that malic acid is the primary organic acid (Denev et al., 2018; Kulling and Rawel, 2008).

\subsection{Polyphenols}

Aronia berry has a significantly higher polyphenol and antioxidant content than most fruits and vegetables (Nour et al., 2015; Jakobek and Seruga, 2012; Pérez-Jiménez, 2010). Aronia berry total polyphenols range from 1.0 to $3.6 \mathrm{~g} / 100 \mathrm{~g}$ fwb (Denev et al., 2018; Nour et al., 2015). The primary polyphenols in aronia berries include anthocyanins, proanthocyanidins, flavonols, and phenolic acids. These polyphenols contribute to the health ben- 
Table 4. Lipid content and profile of aronia berry fruit and pomace.

\begin{tabular}{|c|c|c|c|}
\hline Lipid component & Fruit $(\%)^{+}$ & Pomace $(\%)^{\dagger}$ & Seed oil $(\mathrm{g} / \mathrm{kg})^{+}$ \\
\hline total fat & $0.14^{\mathrm{a}}$ & $2.9-13^{b}$ & - \\
\hline phospholids & - & - & $2.8^{d}$ \\
\hline sterols & - & - & $1.2^{\mathrm{d}}$ \\
\hline tocopherols & - & - & $0.0555^{d}$ \\
\hline \multicolumn{4}{|l|}{ fatty acid } \\
\hline C8:0 & - & $0.02^{c}$ & - \\
\hline $\mathrm{C} 12: 0$ & - & $0.07^{c}$ & $N D^{d}$ \\
\hline $\mathrm{C} 14: 0$ & - & $0.12^{\mathrm{c}}$ & $\operatorname{tr}^{d}$ \\
\hline C16:0 & - & $5.48^{c}$ & $5.1^{\mathrm{d}}$ \\
\hline C16:1 & - & $0.19^{c}$ & $\operatorname{tr}^{d}$ \\
\hline C18:0 & - & $1.71^{\mathrm{c}}$ & $1.1^{\mathrm{d}}$ \\
\hline C18:1 & - & $16.38^{c}$ & $21.4^{d}$ \\
\hline C18:2 & - & $43.43^{c}$ & $71.1^{\mathrm{d}}$ \\
\hline Gamma 18:3 & - & $0.03^{c}$ & - \\
\hline C18:3 & - & $29.78^{c}$ & $0.5^{d}$ \\
\hline CLA c9-t11 & - & $0.01^{c}$ & - \\
\hline C18:4 & - & $0.02^{\mathrm{c}}$ & - \\
\hline $\mathrm{C} 20: 0$ & - & $1.52^{\mathrm{c}}$ & $N D^{d}$ \\
\hline C20:1 & - & $0.33^{c}$ & - \\
\hline$C 20: 2$ & - & $0.14^{c}$ & - \\
\hline $\mathrm{C} 22: 0$ & - & $0.59^{c}$ & $0.8^{d}$ \\
\hline$C 22: 5$ & - & $0.17^{c}$ & - \\
\hline SFA & - & $9.51^{c}$ & $0.7^{d}$ \\
\hline UFA & - & $90.49^{c}$ & - \\
\hline PUFA n-6 & - & $43.6^{c}$ & - \\
\hline PUFA n-3 & - & $29.97^{c}$ & - \\
\hline PUFA n-6/n-3 & - & $1.45^{c}$ & - \\
\hline
\end{tabular}

Abbreviations: CLA, conjugated linoleic acid; SFA, saturated fatty acid; UFA, unsaturated fatty acid; ND, not detected; tr, less than $0.1 \mathrm{~g} / \mathrm{kg}$; PUFA, polyunsaturated fatty acid. ${ }^{\dagger}$ Total

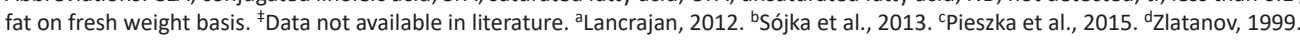

efits as well as the astringent and bitter flavor associated with aronia berry.

\subsubsection{Anthocyanins}

Within black aronia berry, anthocyanins are the most abundant polyphenol and pigment (Wathon et al., 2019; Sidor and GramzaMichałowska, 2019). The structure of anthocyanins determines the pigmentation of the fruit by the type of aglycon base or flavylium ring, sugar, and acylation (Sidor and Gramza-Michałowska, 2019). Anthocyanins also reduce photooxidation and limit $\mathrm{CO}_{2}$ assimilation in plant tissue. Thus, most of the anthocyanins are located on the skin's external layer in the pomace (Veberic et al., 2015). There are six major anthocyanin aglycons in berries: cyanidin, delphinidin, petunidin, peonidin, pelargonidin, and malvidin, which typically contain a sugar moiety (Bueno et al., 2012). In aronia berry, cyanidin glycosides account for 90 to $98.7 \%$ of the total anthocyanin content (Veberic et al., 2015; Denev et al., 2018). The major cyanidin glycosides are include its 3-galactoside (126 to 990 $\mathrm{mg} / 100 \mathrm{~g} \mathrm{fwb}$ ), 3-glucoside (1.7 to $21.5 \mathrm{mg} / 100 \mathrm{~g}$ fwb), 3-arabinoside ( 52 to $399 \mathrm{mg} / 100 \mathrm{~g}$ ), 3-xyloside $(2.7$ to $81.2 \mathrm{mg} / 100 \mathrm{~g}$ fwb), 3,5-hexoside (epi)catechin (14.3 mg/100 g dwb), 3-pentoxide-(epi)catechin $(7.26 \mathrm{mg} / 100 \mathrm{~g} \mathrm{dwb}), 3$-hexoside-(epi)cat-(epi) cat (13.6 mg/100 g dwb) (Table 7). On a fresh weight basis, aronia berries are among the richest dietary sources of anthocyanins (Denev et al., 2018; Pérez-Jiménez et al., 2010).

\subsubsection{Proanthocyanidins}

Aronia contains proanthocyanidins with predominately (-)-epicatechin units $(32.2$ to $99.6 \mathrm{mg} / 100 \mathrm{~g})$ with a trace amount of (+)-catechin (Table 8, Jurikova et al., 2017). Oligomeric and polymeric 
Table 5. Micronutrient, nitrate/nitrite, and mineral content of aronia berry fruit

\begin{tabular}{|c|c|c|}
\hline \multicolumn{2}{|l|}{ Component } & \multirow{2}{*}{$\begin{array}{l}\text { Mass in fruit }(\mathrm{mg} / 100 \mathrm{~g} \mathrm{fwb}) \\
7.25-98.75^{\mathrm{a}}\end{array}$} \\
\hline vitamins & vitamin C & \\
\hline & vitamin A & $0.77^{b}$ \\
\hline & vitamin $\mathrm{E}$ & $0.008-0.031^{c}$ \\
\hline & vitamin B2 & $0.873^{h}$ \\
\hline & vitamin B5 & $2.845^{\mathrm{h}}$ \\
\hline & vitamin B6 & $1.132^{\mathrm{h}}$ \\
\hline & vitamin B7 & $0.615^{\mathrm{h}}$ \\
\hline \multirow[t]{2}{*}{ nitrate/nitrite } & nitrate & $4.520-9.850^{d}$ \\
\hline & nitrite & $0.062-0.187^{d}$ \\
\hline \multirow[t]{26}{*}{ minerals } & $\mathrm{Na}$ & $0.427-1.18^{e, f}$ \\
\hline & K & $135-679 g, f$ \\
\hline & $\mathrm{Ca}$ & $11.9-116.7^{g, e}$ \\
\hline & $\mathrm{Mg}$ & $8.3-66.9 \mathrm{~g}, \mathrm{f}$ \\
\hline & $P$ & $23.9-95.6^{\mathrm{e}}$ \\
\hline & $\mathrm{Zn}$ & $0.055-0.84^{f, e}$ \\
\hline & $\mathrm{Fe}$ & $0.132-1.42^{\mathrm{f}, \mathrm{e}}$ \\
\hline & $\mathrm{Se}$ & $0.0021-0.0028^{f}$ \\
\hline & $\mathrm{Cu}$ & $0.82-.211^{f}$ \\
\hline & Mo & $0.0016-0.0021^{f}$ \\
\hline & $\mathrm{Mn}$ & $0.132-1.789^{f}$ \\
\hline & $\mathrm{Ni}$ & $0.0143-0.0740^{f}$ \\
\hline & V & $0.0040-0.0158^{f}$ \\
\hline & $\mathrm{Si}$ & $0.237-0.637^{f}$ \\
\hline & $\mathrm{Cr}$ & $0.035-0.211^{f}$ \\
\hline & $\mathrm{Li}$ & $0.0016-0.0021^{f}$ \\
\hline & $\mathrm{Sr}$ & $0.132-1.789^{f}$ \\
\hline & Al & $0.288-0.440^{f}$ \\
\hline & Sn & $0.062-0.072^{f}$ \\
\hline & As & $0.020-0.036^{f}$ \\
\hline & $\mathrm{Cd}$ & $0.0016-0.0041^{f}$ \\
\hline & $\mathrm{Ba}$ & $0.148-0.666^{f}$ \\
\hline & $\mathrm{Pb}$ & $0.0048-0.0091^{f}$ \\
\hline & $\mathrm{Sb}$ & ND-0.029f \\
\hline & Co & $0.0019-0.0043^{f}$ \\
\hline & B & $0.288-1.422^{f}$ \\
\hline
\end{tabular}

Abbreviations: fwb, fresh weight basis. '⿳C口冖ană et al., 2017. 'bancrajan, 2012. 'Borowska and Brzóska, 2016. dOchmain et al., 2012. ePavlović et al., 2015. fJuranović Cindrić et al.,

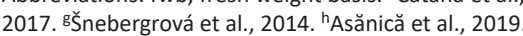

(-)-epicatechins make up monomers, dimers, tetramers, hexamers, octamers, and decamers, but most proanthocyanidins in aronia berries have polymerization greater than 10 (Taheri et al., 2013). Aronia berry proanthocyanidins are distributed $70 \%$ in the flesh, $25 \%$ in the skin, and 5\% in the seeds (Mayer-Miebach et al., 2012).
Proanthocyanidin consumption may have a wide range of human health benefits, including reducing oxidative stress, improving blood circulation, and reducing cancer symptoms (Rauf et al., 2019). Additionally, when used as food ingredients, proanthocyanidins create foamability, oxidative stability, and heat stability and 
Table 6. Organic acid content of aronia berry and juice

\begin{tabular}{|c|c|c|}
\hline Acid & Mass in fruit (mg/100 g fwb) & Mass in juice $(\mathrm{mg} / 100 \mathrm{~mL})$ \\
\hline quinic acid & $293-474^{a}$ & $280^{\mathrm{b}}$ \\
\hline malic acid & $308-350^{a}$ & $708^{b}$ \\
\hline ascorbic acid & 56. $9-72.2^{a}$ & $4^{b}$ \\
\hline shikimic acid & $8.76-8.99^{a}$ & $6^{\mathrm{b}}$ \\
\hline citric acid & $31.1-33.5^{\mathrm{a}}$ & $7^{b}$ \\
\hline oxalic acid & $3.21-3.39^{a}$ & $--^{+}$ \\
\hline succinic acid & $7.08-7.48^{a}$ & - \\
\hline fumaric acid & - & $5.1-10.7^{d}$ \\
\hline tartaric acid & - & $32.1-207^{d}$ \\
\hline isocitric acid & $2.25-3.73^{c}$ & - \\
\hline
\end{tabular}

Abbreviations: fwb, fresh weight basis. ${ }^{\dagger}$ Data not available in literature. ${ }^{a}$ Denev et al., 2018. b Markkinen et al., 2019. cŠnebergrová et al., $2014 .{ }^{d}$ Djuric et al., 2015.

Table 7. Anthocyanin content and profile of aronia berry, juice, and pomace

\begin{tabular}{|c|c|c|c|}
\hline Anthocyanin & $\begin{array}{l}\text { Mass in fruit } \\
(\mathrm{mg} / 100 \mathrm{~g} \mathrm{fwb})\end{array}$ & $\begin{array}{l}\text { Mass in juice } \\
(\mathrm{mg} / 100 \mathrm{~mL})\end{array}$ & $\begin{array}{l}\text { Mass in pomace } \\
(\mathrm{mg} / 100 \mathrm{~g} \mathrm{dwb})\end{array}$ \\
\hline total anthocyanins & $284-631^{a}$ & & \\
\hline cyanidin-3-galactoside & $126-990^{b}$ & $87.4-94.0^{a}$ & $4520-9760^{f}$ \\
\hline cyanidin-3-glucoside & trace- $21.5^{b, c}$ & $10.2-13.5^{a}$ & $21-225.8^{f}$ \\
\hline cyanidin-3-arabinoside & $52-392^{c, d}$ & $24.7-58.6^{a}$ & $1840-3120^{f}$ \\
\hline cyanidin-3-xyloside & $2.7-81.2^{c, d}$ & $0.48-1.25^{a}$ & $167-275^{f}$ \\
\hline pelargonidin-3-arabinoside & $5.04^{e}$ & & \\
\hline cyanidin-3,5-hexoside-(epi)catechin & & & $14.3^{f}$ \\
\hline cyanidin-3-pentoside-(epi)catechin & & & $7.26^{f}$ \\
\hline cyanidin-3-hexoside-(epi)cat-(epi)cat & & & $13.6^{f}$ \\
\hline
\end{tabular}

Abbreviations: fwb, fresh weight basis; dwb, dry weight basis. ${ }^{a}$ Denev et al., 2018. ${ }^{b}$ Borowska and Brzóska, 2016. ${ }^{\mathrm{c} W a n g e n s t e e n}$ et al., 2014. ${ }^{\mathrm{d}} \mathrm{Hwang}$ and Thi, 2016. ${ }^{\mathrm{e}}$ Veberic et al., 2015. 'Oszmiański and Lachowicz, 2016.

Table 8. Tannin content and profile of aronia berry and pomace

\begin{tabular}{|c|c|c|}
\hline Proanthocyanidin & Mass in fruit $(\mathrm{mg} / 100 \mathrm{~g} \mathrm{fwb})^{\dagger}$ & Mass in pomace $(\mathrm{mg} / 100 \mathrm{~g} \mathrm{dwb})^{\ddagger}$ \\
\hline total tannins & $522-1000^{a}$ & $6200-9720^{c}$ \\
\hline monomers (total) & $5.17^{b}$ & - \\
\hline (-)-epicatechin & $62.9-124^{a}$ & - \\
\hline dimers & $12.5^{\mathrm{a}}$ & - \\
\hline procyanidin B2 & - & $21.9-28.2^{c}$ \\
\hline trimers & $10.3^{a}$ & - \\
\hline tetramers & $0.7^{a}$ & - \\
\hline pentamers & $0.75^{a}$ & - \\
\hline hexamers & $1.04^{\mathrm{a}}$ & - \\
\hline heptamers & $0.56^{a}$ & - \\
\hline octamers & $0.51^{a}$ & - \\
\hline decamers & $0.16^{a}$ & - \\
\hline$>10$-mers & $69^{a}$ & \\
\hline
\end{tabular}

Abbreviations: fwb, fresh weight basis; dwb, dry weight basis; -, data not available in literature. ${ }^{\dagger}$ Data for monomers through $>10$-mers as (-)-epicatechin equivalents. ${ }^{\ddagger}$ Data for monomers through > 10-mers as (+)-catechin equivalents. ${ }^{a}$ Denev et al., 2018. ${ }^{b}$ Dudonné et al., 2015. 'Oszmiański and Lachowicz, 2016. 
Table 9. Flavonol content reported in aronia berry fruit, juice, and pomace

\begin{tabular}{llll}
\hline Flavonols & Mass in fruit $(\mathrm{mg} / 100 \mathrm{~g} \mathrm{fwb})$ & Mass in juice $(\mathrm{mg} / 100 \mathrm{~mL})$ & Mass in pomace $(\mathrm{mg} / 100 \mathrm{~g} \mathrm{dwb})$ \\
\hline quercetin-3-rutinoside & $3.9-61.7^{\mathrm{a}}$ & $15.5-62.8^{\mathrm{a}}$ & $22.7-43.7^{\mathrm{d}}$ \\
quercetin-3-glucoside & $4.4-29.2^{\mathrm{a}, \mathrm{b}}$ & $11.5-36.7^{\mathrm{a}}$ & $32.7-67.1^{\mathrm{d}}$ \\
quercetin & $6.5-30.2^{\mathrm{a}, \mathrm{c}}$ & $6.8-8.2^{\mathrm{a}}$ & - \\
quercetin-3-galactoside & $6.6-30.2^{\mathrm{a}, \mathrm{c}}$ & - & $49.0-102^{\mathrm{d}}$ \\
quercetin-3-robinobioside & $1.03-11.3^{\mathrm{a}}$ & - & $14.9^{\mathrm{e}}$ \\
quercetin-3-vicianoside & $2.6-4.3^{\mathrm{a}}$ & - & $19.6^{\mathrm{e}}$ \\
isorhamnetin pentoside hexoside & $1.12^{\mathrm{f}}$ & - & - \\
isorhamnetin 3-O-neohesperidoside & $1.16^{\mathrm{f}}$ & - & - \\
isorhamnetin 3-O-rutinoside & $0.83^{\mathrm{f}}$ & - & - \\
\hline
\end{tabular}

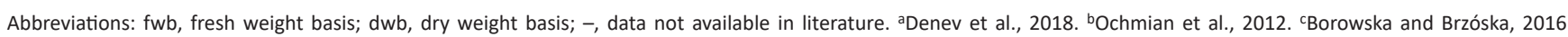

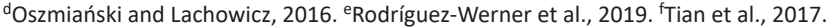

increase astringency (Shi et al., 2003).

\subsubsection{Flavonols}

Flavonols are less abundant in aronia berry relative to proanthocyanidins and anthocyanins. The major flavonol in aronia is quercetin (Table 9), and it can increase by $5 \%$ during juice pasteurization (Jurikova et al., 2017). Quercetin distributed as its 3-rutinoside (3.9 to $61.7 \mathrm{mg} / 100 \mathrm{~g}$ fwb), 3-glucoside (4.03 to $29.2 \mathrm{mg} / 100 \mathrm{~g}$ fwb), 3-galactoside (6.6 to $30.2 \mathrm{mg} / 100 \mathrm{~g} \mathrm{fwb}$ ), 3-robinobioside (1.03 to $11.3 \mathrm{mg} / 100 \mathrm{~g} \mathrm{fwb}), 3$-vicianoside $(2.36-5.38 \mathrm{mg} / 100 \mathrm{~g}$ fwb) (Table 9). Other aronia berry flavonols include myricetin, isorhamnetin, and kaempferol.

\subsubsection{Phenolic acids}

The phenolic acid profile of aronia berries is mainly neochlorogenic and chlorogenic acids with lower levels of other phenolic ac- ids (Table 10). These other phenolic acids include vanillic, ferulic, syringic, and gallic acids.

\subsubsection{Non-extractable polyphenols}

In the studies reviewed, most of the experiments have used analytical methods to assess extractable polyphenols (EPs).The solvents used to obtain EPs are typically aqueous-organic, commonly containing water, methanol, or acetone (Han et al., 2019). In contrast, non-extractable polyphenols (NEPs), also known as insolublebound phenolics, require enzymatic, acidic, or alkaline hydrolysis to be liberated to the extraction medium (de Camargo et al., 2016). These methods dissociate non-extractable polyphenols from cellulose, hemicellulose, polysaccharides, and polypeptides. Advanced techniques, such as ultrasound-assisted extraction and microwaveassisted extraction, are not able to successfully extract NEPs. The most effective method to release the NEPs is hydrolysis (Dzah et al., 2020). However, hydrolysis conditions may degrade polyphenols. After juicing, aronia pomace is a good source of NEPs.

Table 10. Phenolic acid content reported in aronia berry fruit, juice and pomace

\begin{tabular}{llll}
\hline Phenolic acid & Mass in fruit (mg/100 g fwb) & Mass in juice $(\mathbf{m g} / 100 \mathrm{~mL})$ & Mass in pomace $(\mathrm{mg} / \mathbf{1 0 0} \mathrm{g} \mathrm{dwb})$ \\
\hline neochlorogenic acid & $59-186^{\mathrm{a}, \mathrm{b}}$ & $41.6-172^{\mathrm{a}, \mathrm{f}}$ & $169^{\mathrm{j}}$ \\
chlorogenic acid & $17-188^{\mathrm{a}, \mathrm{c}}$ & $88.6-139^{\mathrm{a}}$ & $204^{\mathrm{j}}$ \\
caffeic acid & $60-75^{\mathrm{a}, \mathrm{c}}$ & $0.12-0.18^{\mathrm{g}}$ & - \\
protocatechuic acid & $0.77^{\mathrm{d}}$ & $2.49-5.74^{\mathrm{f}}$ & - \\
vanillic acid & $0.25-0.46^{\mathrm{c}}$ & - & - \\
p-Coumaric acid & $0.02^{\mathrm{d}}$ & - & - \\
dicaffeoylquinic acid & $3.74^{\mathrm{e}}$ & - & - \\
ferulic acid & $0.01^{\mathrm{d}}$ & $1.99^{\mathrm{h}}$ & $4.16^{\mathrm{k}}$ \\
syringic acid & - & - & - \\
ellagic acid & $1.57^{\mathrm{d}}$ & - & - \\
gallic acid & - & $0.004-0.69^{\mathrm{h}, \mathrm{i}}$ & - \\
salicylic acid & - & - & \\
\hline
\end{tabular}

Abbreviations: fwb, fresh weight basis; dwb, dry weight basis; -, data not available in literature. ${ }^{\mathrm{a} D e n e v}$ et al., 2018. ${ }^{\mathrm{b}}$ Ochmian et al., 2012. ' $\mathrm{Hwang}$ and Thi, 2016. dDudonné et al.,

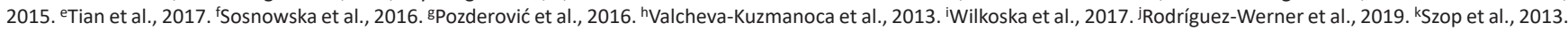


Enzyme-assisted extraction and high-pressure extraction methods have also been applied to recover NEPs from aronia berry pomace (Grunovaite et al., 2016; Kitrytė et al., 2017); however, alkaline hydrolysis is expected to be the most efficient method to recover NEPs (de Camargo et al., 2016). The profile of aronia berry NEPs recovered by enzyme- assisted extraction and high-pressure extraction is similar to its free polyphenol profile (Grunovaite et al., 2016; Kitrytė et al., 2017).

\subsection{Astringent compounds}

Although aronia berries show potential for numerous health benefits, consumption of whole aronia berry is limited by its astringency and bitterness. Adding sugar or ethyl butyrate to aronia juice may reduce its bitterness, but does not change astringency and consumers' preference (Duffy et al., 2016). Amygdalin is an aromatic cyanogenic glucoside compound that is responsible for a bitter-almond smell and contributes to aronia berry astringency. There are no recent studies on amygdalin content in aronia berries, but prior studies have reported $52.3 \mathrm{mg} / 100 \mathrm{~g}$ fwb in pomace (Kulling and Rawel, 2008). Proanthocyanidins also contribute to astringency, due to its interactions with salivary proteins (Soares et al., 2018). Some hydroxycinnamic acids, including vanillic and syringic acid, may also contribute to astringency (Sáenz-Navajas et al., 2010). Additional research to characterize the relative astringency of these components in aronia berries can help inform product development and masking strategies in food production.

\section{Polyphenol bioavailability}

Aronia berries contain higher antioxidant capacity than most foods (Pérez-Jiménez et al., 2010), but these tests neglect polyphenol metabolism and bioavailability. Thus, to understand the antioxidant and human health-promoting mechanisms of aronia polyphenol consumption, it is necessary to consider the metabolism and bioavailability of its polyphenols. While reports on polyphenol bioavailability have increased, there is still limited knowledge about the dynamics of polyphenol metabolism (Neilson et al., 2017; Shahidi et al., 2019). Bioavailability depends on their physicochemical stability, complex formation, food interaction, gastrointestinal absorption, and hepatic and gut metabolism (Luca et al., 2019). Recent work has described how the gut microbiome contributes to aronia polyphenol metabolism and bioavailability (Istas et al, 2019). Significant inter-individual variability of polyphenol metabolism and bioavailability may explain the variable outcomes in human intervention studies and are summarized in Table 11. The following subsections focus on describing the metabolism and bioavailability of aronia berry polyphenols.

\subsection{Anthocyanins}

Anthocyanin structure and stability is $\mathrm{pH}-\mathrm{dependent.} \mathrm{Upon} \mathrm{con-}$ sumption, the oral cavity $\mathrm{pH}$ is 5.6-7.9, which enhances anthocyanin hydrolysis. Given the short time period at this $\mathrm{pH}$, only a fraction are hydrolyzed in the oral cavity (Braga et al., 2018). In the stomach, the acidic $\mathrm{pH}$ of 1.5-3.5 increases the proportion of anthocyanins as flavylium cations (Braga et al., 2018). At the small intestine, the $\mathrm{pH}$ of 6.7 to 7.4 favors the anthocyanin chalcone and quinoidal base formation, promoting hydrolysis to low molecular weight phenolics (Braga et al., 2018). A fraction of anthocyanins are directly absorbed in the stomach and small intestine. However, anthocyanins have low absorption in the small intestine, and the majority of them will be catabolized by gut microbiota (Denev et al., 2012). Upon absorption, anthocyanins and their metabolites undergo phase I and phase II metabolism in enterocytes and the liver (Denev et al., 2012). Phase I metabolites include phloroglucinaldehyde, 3,4-dihydroxybenzaldehyde, and hydroxybenzoic acid. Phase II metabolites are glucuronidated and methylated cyanidin. In the colon, gut microbiota hydrolyzes the anthocyanins into phenolic acids such as hippuric acid, phenylpropanoid acid, and ferulic acid (Wiczkowski et al., 2010; Denev et al., 2012). A human supplementation study utilizing ${ }^{13} \mathrm{C}$-cyanidin-3-glucoside reported $5.4 \%$ urinary excretion of anthocyanins and its metabolites (Czank et al., 2013). It would be expected that cyanidin-3-galactoside metabolism would be similar (Figure 1).

\subsection{Proanthocyanidins}

Proanthocyanidins have limited bioavailability because of their polymeric structures. Larger polymers are unable to translocate across the phospholipid bilayer of intestinal cells membrane, be transported by carrier proteins, and entirely dissolve into the aqueous phase of the small intestine (Luca et al., 2019). Moreover, human enzymes are not able to hydrolyze proanthocyanidins. Therefore, only monomers or dimers can be absorbed in the small intestine (Williamson and Clifford, 2017). The majority of proanthocyanidins reach the colon unchanged. A proportion of B-type proanthocyanidins are hydrolyzed by gut microbiota to valerolactones and phenolic acids (Appeldoorn et al., 2009). Thus, phenolic catabolites' rate and profile are highly dependent on the gut microbial composition (Luca et al., 2019). The remaining proanthocyanidins are excreted and in the feces (Neilson et al., 2016).

\subsection{Quercetin}

The metabolism and bioavailability of quercetin depends on its glycosylation (Kaşıkcı and Bağdatlığlu, 2016). Quercetin glucosides and galactosides are absorbed in the small intestine, whereas rutinosides are not. Rutin (quercetin-3-rutinoside) is deglycosylated by microbiota and then absorbed through passive diffusion (Luca et al., 2019). Quercetin glucosides and galactosides are hydrolyzed in the gut and liver, and aglycones mainly undergo Phase II metabolism. If the flavonols are not absorbed in the small intestine, they enter the gut, where the microbiota hydrolyzes the quercetin (Luca et al., 2019). The bacteria hydrolyze quercetin to low molecular polar metabolites (Santhakumar et al., 2018). Some of these compounds are 4-dihydroxyphenylacetic acid (DOPAC), 3-hydroxyphenyl acetic acid (3-OPAC), 3,4-dihydroxybenzoic acid (PCA), and vanillic acid (Ameida et al., 2018). The rate of formation of microbial metabolites depends in-part on nutrients presence (Rodriguez-Castaño et al., 2019). These low molecular compounds are absorbed in the large intestine and then metabolized in the liver (Atala et al., 2017). Quercetin metabolites are excreted through feces and urine, mainly as benzoic and hippuric acid (Luca et al., 2019).

\subsection{Phenolic acids}

The predominant phenolic acids in aronia, chlorogenic and neochlorogenic acids, require de-esterification of quinic acid prior to absorption (Denev et al., 2012). The bioavailability of these com- 


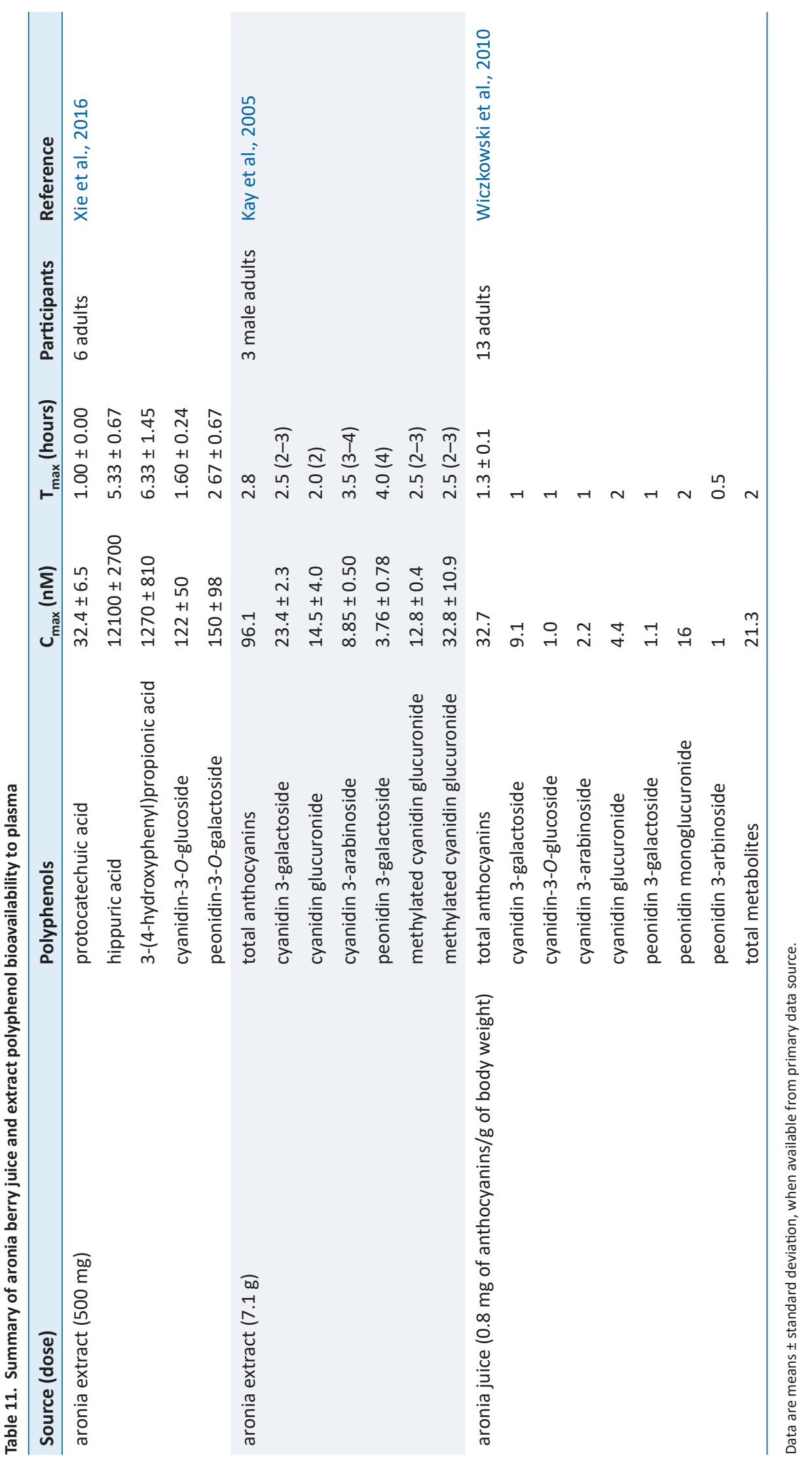


pounds are low because esterase is limited in the small intestine. In the colon, bacteria release caffeic acid from chlorogenic acid (Heleno et al., 2015). Subsequently, absorbed phenolic acids undergo phase II metabolism in tissues prior to excretion.

\subsection{Aronia polyphenol bioavailability}

The maximum plasma concentration of dietary polyphenols in humans is in the nanomolar or low micromolar range (Istas et al., 2019). The highest level of polyphenols reported in plasma after aronia consumption has been 1.4 and $592 \mathrm{nmol} / \mathrm{L}$, and appearing in the plasma between 0.5 and $4 \mathrm{~h}$ after consumption (Pojer et al., 2013). This wide range of absorption is partly because of differences in fruit composition, glycosylation, and anthocyanidin type. For example, a review on anthocyanins bioavailability concluded that galactosides were more bioavailable than arabinosides (Pojer et al., 2013). Additionally, the report compared aronia berry and elderberry extract bioavailability, containing $721 \mathrm{mg}$ and $720 \mathrm{mg}$ anthocyanidins, respectively (Pojer et al., 2013; Cao et al., 2001; Kay et al., 2005). After participants consumed both extracts, plasma anthocyanin concentrations were similar at $96.08 \mathrm{nM}$ and $97.20 \mathrm{nM}$, respectively (Cao et al., 2001; Kay et al., 2005). In a double-blind, placebo-controlled study compared polyphenol metabolites in plasma after the consumption of whole aronia fruit or aronia extract (Istas et al., 2019). The total plasma polyphenol concentration was $30 \pm 156 \mu \mathrm{M}$ and 14 $\pm 106 \mu \mathrm{M}$ after 12 weeks of consuming extract and whole berries, respectively (Table 11). In addition, 20 metabolites were found in the volunteers consuming aronia extract, while only five metabolites were found after whole fruit consumption.

Another study evaluated the pharmacokinetics of anthocyanins and selected metabolites in adults' plasma $(n=6)$ that consumed $500 \mathrm{mg}$ of aronia extract (Xie et al., 2016). Hippuric acid had the highest plasma concentration ( 0.87 to $3.5 \mu \mathrm{g} / \mathrm{mL})$, followed by 3-(4-hydroxyphenyl)propionic acid $(0.033$ to $0.48 \mu \mathrm{g} / \mathrm{mL})$, peonidin-3-O-galactoside $(0.029$ to $0.266 \mu \mathrm{g} / \mathrm{mL})$, cyanidin-3-O-glucoside $(0.014$ to $0.180 \mu \mathrm{g} / \mathrm{mL})$, and lastly protocatechuic acid $(0.004$ to $0.007 \mu \mathrm{g} / \mathrm{mL}$ ) (Xie et al., 2016). A separate study found eight metabolites in the blood and urine consuming of $0.8 \mathrm{mg}$ of anthocyanins/ $\mathrm{kg}$ of body weight from aronia juice (Wiczkowski et al., 2010). The concentration of anthocyanins in the plasma was maximal at 1.3 hours after consumption, reaching 20.4 to $51.8 \mathrm{nmol} / \mathrm{L}$. However, all of these studies had significant inter-individual variability in polyphenol pharmacokinetics. Larger studies are needed to characterize the importance of these variations to human health.

\section{Health benefits of aronia berry consumption}

Non-communicable diseases (cancer, diabetes, cardiovascular diseases, and depression) have an enormous social and economic toll worldwide (Centers for Disease Control and Prevention, 2020). Thus, multiple studies have focused on effective treatments to lower the risks of non-communicable diseases. Given the high polyphenol content of aronia berries, preliminary evidence indicates its preventive and therapeutic effects on non-communicable diseases. Here, we summarize recent preclinical (Table 12) and human intervention studies (Table 13) with aronia berry, juice, or extracts.

\subsection{Cancer prevention}

Recent studies have demonstrated anti-carcinogenic mechanisms of aronia polyphenols in vitro. Aronia extract prevents the growth, migration, and invasion of SK-Hep1 human liver cancer cells (Thi and Hwang, 2018). Liver cancer cell growth, adhesion, and migration were reduced by the aronia extract. Furthermore, aronia extract inhibited the expression of proteases involved in metastasis (MMP-2/9, MT-1 MMP). Another study isolated catechol from fermented aronia juice and characterized its inhibition of cancer stem cells (Choi et al., 2018). Catechol inhibited the formation of cancer stem cells and reduced the production of IL-6, which enhances cancer cells' survival. Additionally, catechol inhibited Stat3, a key transcription factor necessary for cancer stem cell formation. Thus, aronia components can inhibit multiple cancer mechanisms in vitro. Further studies that account for aronia polyphenol and bioavailability are needed to determine these studies' relevance to human health.

\subsection{Diabetes}

Preclinical and human studies have reported that aronia consumption may reduce insulin resistance. In rodents, aronia juice concentrate consumption increased plasma levels of adiponectin, the most abundant peptide secreted by key monomers that have an interrelationship between insulin resistance and inflammation (Baum et al., 2016). Aronia juice consumption also decreased intestinal glucosidase activity and increased DPP IV activity in diabetic mice (Yamane et al., 2016). An open-label trial of aronia juice for adults with type 2 diabetes reported improvement of glycemic control, with decreased fasting blood glucose and glycated hemoglobin (Milutinović et al., 2019). Thus, aronia consumption appears to be a promising treatment for diabetes. Further well-controlled human intervention studies on aronia berry are needed to increase the evidence base for its anti-diabetic activity.

\subsection{Cardiovascular disease}

Cardiovascular disease is a leading cause of death in the US (Centers for Disease Control and Prevention, 2020). Poor diets, low physical activity, excessive drinking, and smoking may increase cardiovascular disease risk. Increased blood pressure, adiposity, total and LDL cholesterol, and elevated inflammation and oxidative stress increase cardiovascular disease risk. Preclinical experiments have demonstrated aronia berry extract increases vasodilatory nitric oxide in cultured endothelial cells, and L-NAME induced hypertensive rats (Varela et al., 2015; Cebova et al., 2017). In rats, this increase is associated with increased nitric oxide synthase activity, reduced inflammation, and hypertension (Cebova et al., 2017). Consumption of aronia berry powder, extract, and juice also inhibits weight gain, lipid dysmetabolism, and inflammation in diet-induced obesity in mice (Bhaswant et al., 2017; Jeong and Kim, 2019; Yamane, Kozuka, Yamamoto, et al., 2016).

Aronia berry consumption improves biomarkers associated with cardiovascular disease risk in human intervention studies, but these changes depend on the participant populations. Aronia extract (116 $\mathrm{mg}$ ) and powder $(12 \mathrm{mg})$ consumption improved flow-mediated dilation, a marker of vascular function, in healthy men (Istas et al., 2019). Consumption of $300 \mathrm{~mL} /$ day of aronia juice and $3 \mathrm{~g}$ /day of aronia powder reduced systolic/diastolic blood pressure in adults with mildly elevated hypertension, but did not modulate serum lipids (Loo et al., 2016). Aronia extract reduced total and LDL cholesterol in healthy former smokers, and these changes were associated with increased urinary excretion of peonidin-3-galactoside, cyanidin-3-galactoside, and 3-(4-hydroxyphenyl)propionic acid (Xie et al., 2017). Open-label trials of aronia juice for adults with type 2 


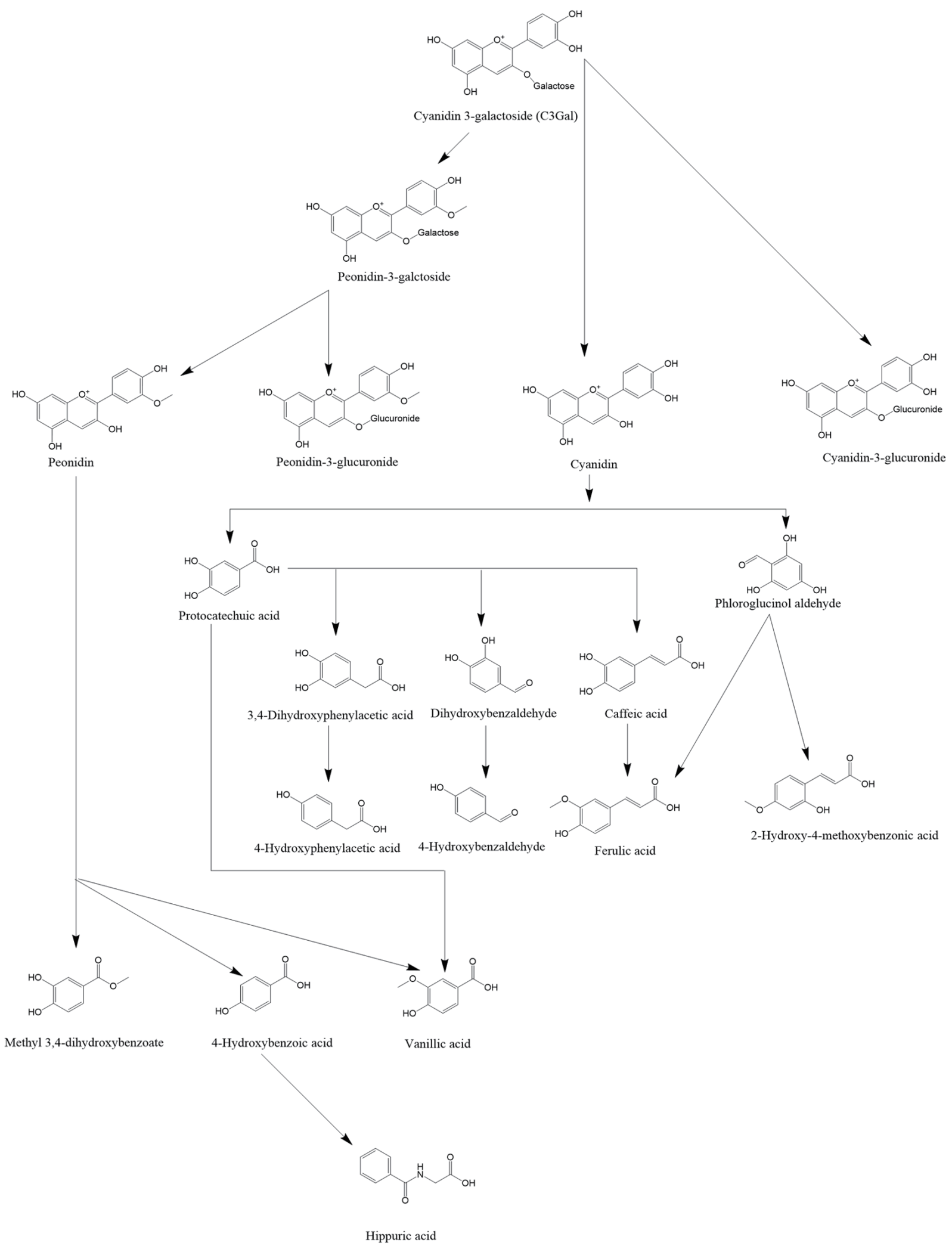

Figure 1. Overview of cyanidin-3-galactoside metabolism, adapted from de Ferrars et al. (2014). Cyanidin-3-galactoside undergoes methylation by the host to form peonidin-3-galactoside, or is hydrolyzed and glucoronidated. Anthyocyanins are subsequently hydrolyzed in host tissue or by the gut microbiota into phenolic acids. Phenolic catabolites can undergo enterohepatic circulation and are subjected to further host metabolism prior to excretion. 


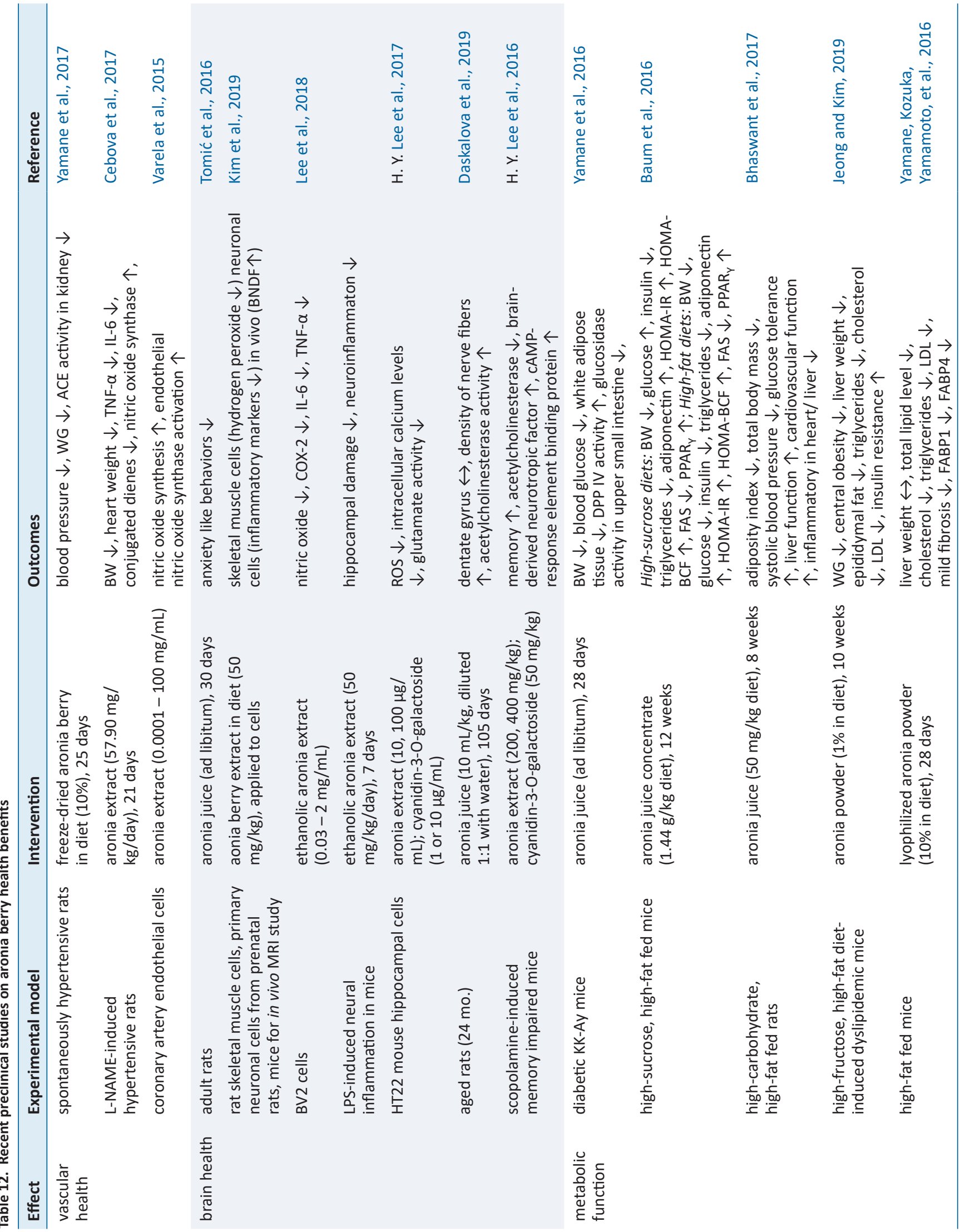



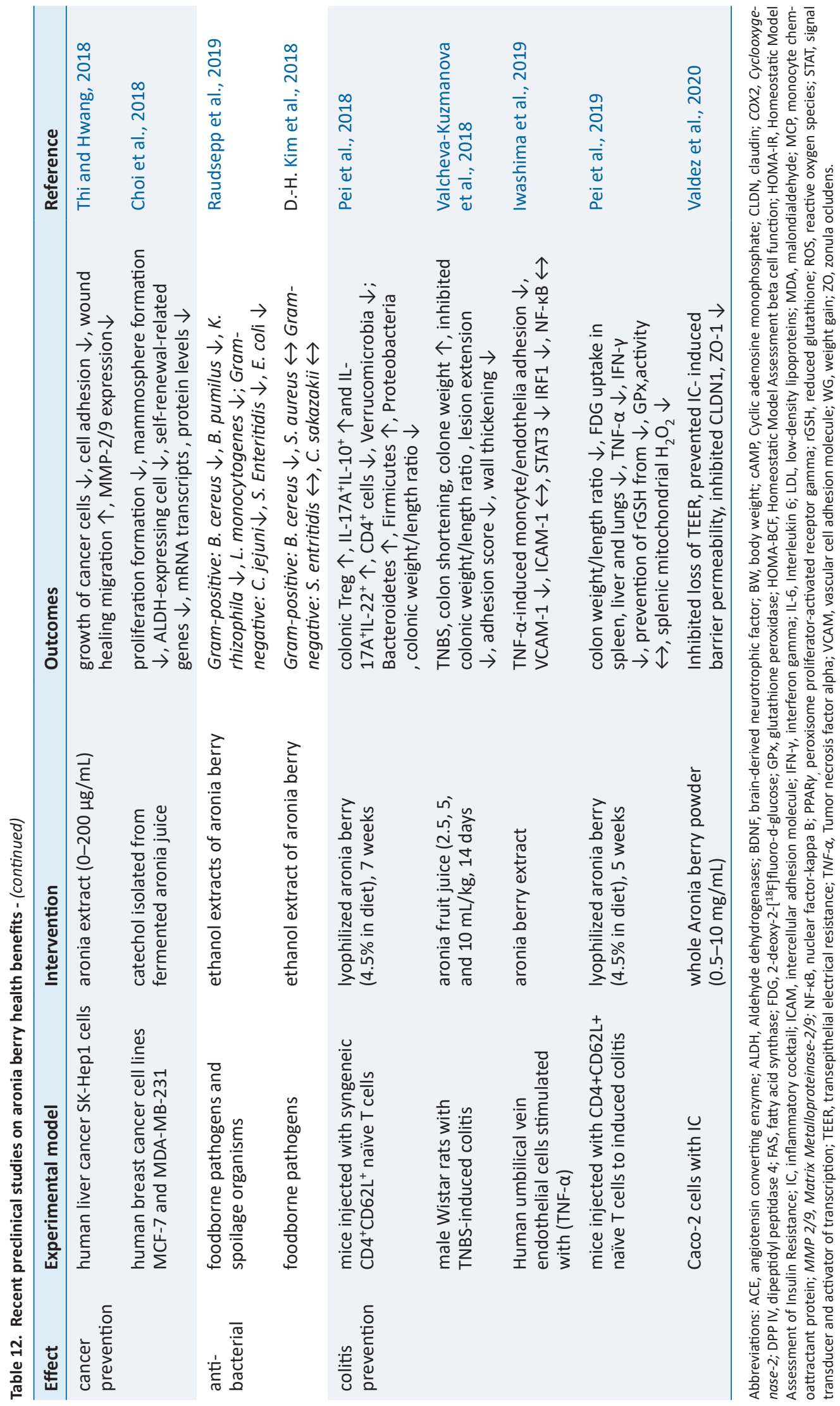
Table 13. Recent human intervention studies with aronia berry interventions

\begin{tabular}{|c|c|c|c|c|}
\hline Participants & Design & Treatment & Outcomes & References \\
\hline healthy men $(n=66)$ & $\begin{array}{l}\text { double-blinded, } \\
\text { placebo- } \\
\text { controlled RCT }\end{array}$ & $\begin{array}{l}\text { (poly)phenol-rich extract } \\
\text { ( } 116 \mathrm{mg} \text {, equivalent } \\
\text { to } 75 \mathrm{~g} \text { berries), whole } \\
\text { fruit powder ( } 12 \mathrm{mg} \text {, } \\
\text { equivalent to } 10 \mathrm{~g} \\
\text { berries), } 12 \text { weeks }\end{array}$ & $\begin{array}{l}\text { Extract: flow-mediated dilation } \uparrow, \text { plasma } \\
\text { phenolic metabolites } \uparrow \text {, gut microbiota } \\
\text { diversity } \leftrightarrow \text {, Anaerostipes: genus } \uparrow \text {, } \\
\text { Bacteroides } \uparrow ; \text { Powder: flow-mediated } \\
\text { dilation } \leftrightarrow \text {, plasma phenolic metabolites } \\
\uparrow, \text { Anaerostipes genus } \uparrow, \text { Bacteroides } \uparrow\end{array}$ & $\begin{array}{l}\text { Istas et al., } \\
2019\end{array}$ \\
\hline $\begin{array}{l}\text { adults with } \\
\text { mildly elevated } \\
\text { hypertension }(n=66)\end{array}$ & $\begin{array}{l}\text { single-blinded, } \\
\text { placebo- } \\
\text { controlled RCT }\end{array}$ & $\begin{array}{l}\text { aronia juice }(300 \mathrm{~mL} / \mathrm{d}) \text {, } \\
\text { oven-dried aronia } \\
\text { powder }(3 \mathrm{~g} / \mathrm{d})\end{array}$ & $\begin{array}{l}\text { blood pressure } \downarrow \text {, low-grade } \\
\text { inflammation (TNF- } \alpha \text {, IL-10) } \downarrow \text {, serum } \\
\text { lipids } \leftrightarrow \text {, serum glucose } \leftrightarrow\end{array}$ & Loo et al., 2016 \\
\hline $\begin{array}{l}\text { adolescents } \\
\text { with metabolic } \\
\text { syntdrome }(n=77)\end{array}$ & open-label & $\begin{array}{l}\text { aronia extract }(3 \times \\
100 \mathrm{mg} / \text { day }), 8 \text { weeks }\end{array}$ & $\begin{array}{l}\text { total cholesterol } \downarrow \text {, LDL } \downarrow \text {, triacylglycerol } \\
\downarrow, \text { HDL } \uparrow \text {, lipid peroxidation } \downarrow \text {, } \\
\text { acetylcholinesterase } \downarrow \text {, oxidative stress } \downarrow\end{array}$ & $\begin{array}{l}\text { Duchnowicz } \\
\text { et al., } 2018\end{array}$ \\
\hline $\begin{array}{l}\text { former smokers } \\
(n=49)\end{array}$ & $\begin{array}{l}\text { single-blinded, } \\
\text { placebo- } \\
\text { controlled RCT }\end{array}$ & $\begin{array}{l}\text { aronia extract (500 } \\
\mathrm{mg} / \text { day), } 12 \text { weeks }\end{array}$ & $\begin{array}{l}\text { Total cholesterol } \downarrow \text {, LDL } \downarrow \text {, LDL receptor } \\
\text { proteins } \downarrow \text {, blood pressure } \leftrightarrow \text {, inflammation } \\
\text { and oxidative stress biomarkers } \leftrightarrow\end{array}$ & Xie et al., 2017 \\
\hline $\begin{array}{l}\text { healthy, adult } \\
\text { handball players } \\
(n=32)\end{array}$ & $\begin{array}{l}\text { double-blinded, } \\
\text { placebo- } \\
\text { controlled RCT }\end{array}$ & aronia juice (100 mL/d), & $\begin{array}{l}\text { Men: lipid peroxidation } \downarrow \text {, oleic acid } \downarrow \text {, } \\
\alpha \text {-linolenic acid } \downarrow, \text { TAG } \downarrow \text {, TBARS } \downarrow ; \text { Women: } \\
\text { lipid peroxidation } \leftrightarrow \text {, TAG } \uparrow \text { TBARS } \leftrightarrow\end{array}$ & $\begin{array}{l}\text { Petrovic et } \\
\text { al., } 2016\end{array}$ \\
\hline $\begin{array}{l}\text { adults with type } 2 \\
\text { diabetes }(n=35)\end{array}$ & open-label & $\begin{array}{l}\text { aronia juice (50 } \mathrm{mL} \\
\times 3 / \mathrm{d}), 3 \text { months }\end{array}$ & $\begin{array}{l}\text { glucose } \downarrow \text {, glycated hemoglobin } \downarrow \text {, total } \\
\text { cholesterol } \downarrow \text {, LDL } \downarrow \text {, HDL } \leftrightarrow \text {, triglycerides } \\
\downarrow \text {, high sensitive C-reactive protein } \uparrow \text {, blood } \\
\text { urea } \downarrow \text {, creatinine } \leftrightarrow \text {, BMI } \leftrightarrow \text {, systolic blood } \\
\text { pressure } \leftrightarrow \text {, diastolic blood pressure } \leftrightarrow\end{array}$ & $\begin{array}{l}\text { Milutinović } \\
\text { et al., } 2019\end{array}$ \\
\hline $\begin{array}{l}\text { healthy, adult } \\
\text { runners }(n=10)\end{array}$ & $\begin{array}{l}\text { double-blinded, } \\
\text { placebo- } \\
\text { controlled RCT }\end{array}$ & $\begin{array}{l}\text { aronia juice ( } 200 \mathrm{~mL} \\
\text { with breakfast prior to } \\
\text { running a half-marathon) }\end{array}$ & $\begin{array}{l}\text { platelet-monocyte aggregates } \downarrow \text {, } \\
\text { platelet-neutrophil aggregates } \downarrow\end{array}$ & $\begin{array}{l}\text { Stevanović } \\
\text { et al., } 2019\end{array}$ \\
\hline
\end{tabular}

Abbreviations: BMI, body mass index; HDL, high-density lipoproteins; IL-10, Interleukin-10; LDL, low-density lipoproteins; TAG, triglycerides; TBARS, thiobarbituric acid reactive substances; TNF- $\alpha$, Tumor necrosis factor alpha.

diabetes and aronia extract for adolescents with metabolic syndrome have also been promising for modulating serum lipids and reducing oxidative stress and inflammation biomarkers. A systematic review and meta-analysis of literature concluded that among human interventions, aronia consumption leads to increases in HDL and diastolic blood pressure (Rahmani et al., 2019). Thus, further trials are needed to strengthen the evidence base for the specific populations that benefit from aronia berry consumption.

\subsection{Modulation of gut microbiota}

The microbiota contributes to modulation of the immune system and is now recognized to contribute to the progression of chronic disease (Festi et al., 2014). Furthermore, the gut microbiota contributes to the development of the metabolic syndrome and affects energy, lipid, and insulin metabolism. Furthermore, diets high in prebiotics that increase commensal microbes may positively change the microbiota composition and reduce inflammation related to metabolic syndrome. In aronia, sorbitol, fiber, and polyphenols may modulate microbial populations. Aronia polyphenols have direct anti-microbial activity against some food pathogens; however, the in vivo modulation of these microbes are not clear (Table 12). In mice, gut microbiota modulation precedes its antiinflammatory and immunomodulatory effects (Pei et al., 2019). In healthy adults, polyphenols' consumption equivalent to $75 \mathrm{~g}$ of aronia berry or berry powder equivalent to $10 \mathrm{~g}$ of aronia berry for 12 weeks did not affect microbial diversity (Istas et al., 2019).
However, both groups had significant increases in Anaerostipes and Bacteroides, which are thought to be beneficial commensals. In a simulated human microbiota experiment, aronia juice increased firmicutes, proteobacteria and Akkermansia (Wu et al., 2018). Further studies are needed to characterize the specific effects of whole aronia berry and juice on gut microbiota and its relationship with inflammation outcomes and other health effects.

\subsection{Neuroprotection}

Experiments in rodents support the neuroprotective effects of aronia consumption (Table 12). When applied to cultured hippocampal and microglial cells, aronia reduces oxidative stress and inflammation (Lee et al., 2018; H. Y. Lee et al., 2017). In aged rats, aronia juice consumption increased hippocampal nerve fibers (Daskalova et al., 2019). Aronia supplementation may improve memory impairment and motor skills in rats (Daskalova et al., 2019; Lee et al., 2018).

Furthermore, aronia juice consumption reduced anxiety-like behaviors in adult rats (Tomić et al., 2016). While more research is necessary, these findings suggest aronia juice or extracts could benefit cognitive function and improve neural health.

\subsection{Colitis}

Colitis leads to dysmetabolism, loss of body weight, and micro- 
biota changes (Ungaro et al., 2019; Pei et al., 2018). Anthocyanins inhibit intestinal inflammation, promote intestinal barrier function, and maybe protective against colitis (Valdez and Bolling, 2019). Aronia berry powder is protective against adoptive transfer and chemical-induced colitis in rodents. In adoptive transfer colitis, aronia consumption reduces colonic CD4+ cells and increases colonic Tregs and anti-inflammatory Th17 (Pei et al., 2018). These changes are linked to reduced oxidative stress and modulation of colonic antioxidant function (Pei et al., 2019). In the trinitrobenzene sulfonic acid (TNBS) colitis model, aronia juice consumption inhibits inflammation (Valcheva-Kuzmanova et al., 2018). The aronia berry juice decreased the lesion extension, adhesion score, and the colon's wall thickening score in colitic Wistar rats. Although these studies are promising, human intervention studies are necessary to determine the efficacy of aronia berry or its coproducts to inhibit inflammatory bowel diseases.

\section{Conclusions}

Aronia berries are one of the richest plant sources of anthocyanins and other bioactive polyphenols. However, these are presently underutilized in the diet because of its sourness and astringency. Aronia extract, juices, and pomace may be useful as functional ingredients, given their polyphenol content. Developing a better understanding of the contribution of bioactives to astringency could help create aronia products with improved palatability. Developing a more complete nutrient profile of aronia berry and juice will help improve nutrient databanks. Establishing the relationship of aronia plant genotype to berry quality will improve the production of berries with increased bioactive content. Emerging evidence describes the beneficial effects of aronia berry for prevention of diabetes, hypertension, cardiovascular disease, cancer, and colitis. However, future studies on the health benefits of aronia berry should utilize well-characterized aronia material, including description of the genotype, polyphenols, sorbitol, fiber, and micronutrient content.

\section{Acknowledgments}

The authors were supported by the USDA Specialty Crop MultiState Program (\#18-13-352).

\section{References}

Almeida, A.F., Borge, G.I.A., Piskula, M., Tudose, A., Tudoreanu, L., Valentová, K., and and Santos, C.N. (2018). Bioavailability of quercetin in humans with a focus on interindividual variation. Comp. Rev. Food Sci. Food Saf. 17(3): 714-731.

Andrzejewska, J., Sadowska, K., Klóska, Ł., and Rogowski, L. (2015). The effect of plant age and harvest time on the content of chosen components and antioxidative potential of black chokeberry fruit. Acta Sci. Pol. Hortorum Cultus. 14: 105-114.

Appeldoorn, M.M., Vincken, J.-P., Aura, A.-M., Hollman, P.C.H., and Gruppen, H. (2009). Procyanidin dimers are metabolized by human microbiota with 2-(3,4-dihydroxyphenyl)acetic acid and 5-(3,4-dihydroxyphenyl)- $\gamma$-valerolactone as the major metabolites. J. Agric. Food Chem. 57(3): 1084-1092.

Asănică, A.C., Catană, L., Catană, M., Burnete, A.G., Lazăr, M.A., Belc, N., and Sanmartin, A.M. (2019). Internal validation of the methods for determination of water-soluble vitamins from frozen fruits by HPLCHRMS. Rom. Biotechnol. Lett. 24(6): 1000-1007.

Atala, E., Fuentes, J., Wehrhahn, M.J., and Speisky, H. (2017). Quercetin and related flavonoids conserve their antioxidant properties despite undergoing chemical or enzymatic oxidation. Food Chem. 234: 479485.

Baum, J.I., Howard, L.R., Prior, R.L., and Lee, S.-O. (2016). Effect of Aronia melanocarpa (Black Chokeberry) supplementation on the development of obesity in mice fed a high-fat diet. J. Berry Res. 6(2): 203-212.

Bhaswant, M., Shafie, S.R., Mathai, M.L., Mouatt, P., and Brown, L. (2017). Anthocyanins in chokeberry and purple maize attenuate diet-induced metabolic syndrome in rats. Nutrition. 41: 24-31.

Bolling, B.W., Taheri, R., Pei, R., Kranz, S., Yu, M., Durocher, S.N., and Brand, M.H. (2015). Harvest date affects aronia juice polyphenols, sugars, and antioxidant activity, but not anthocyanin stability. Food Chem. 187: 189-196.

Borowska, S., and Brzóska, M.M. (2016). Chokeberries (Aronia melanocarpa) and their products as a possible means for the prevention and treatment of noncommunicable diseases and unfavorable health effects due to exposure to xenobiotics. Comp. Rev. Food Sci. Food Saf 15(6): 982-1017.

Braga, A.R.C., Murador, D.C., de Souza Mesquita, L.M., and de Rosso, V.V. (2018). Bioavailability of anthocyanins: Gaps in knowledge, challeng es and future research. J. Food Comp. Anal. 68: 31-40.

Brand, M.H., Connolly, B.A., Levine, L.H., Richards, J.T., Shine, S.M., and Spencer, L.E. (2017). Anthocyanins, total phenolics, ORAC and moisture content of wild and cultivated dark-fruited Aronia species. Sci. Hort. 224: 332-342.

Bueno, J.M., Sáez-Plaza, P., Ramos-Escudero, F., Jiménez, A.M., Fett, R., and Asuero, A.G. (2012). Analysis and antioxidant capacity of anthocyanin pigments. Part II: chemical structure, color, and intake of anthocyanins. Crit. Rev. Anal. Chem. 42(2): 126-151.

Cao, G., Muccitelli, H.U., Sánchez-Moreno, C., and Prior, R.L. (2001). Anthocyanins are absorbed in glycated forms in elderly women: a pharmacokinetic study. Am. J. Clin. Nutr. 73(5): 920-926.

Castañeda-Ovando, A., Pacheco-Hernández, M.d.e.L., Páez-Hernández, M.E., Rodríguez, J.A., and Galán-Vidal, C.A. (2009). Chemical studies of anthocyanins: A review. Food Chem. 113(4): 859-871.

Catană, L., Catană, M., lorga, E., Asănică, A.C., Lazăr, A.G., Lazăr, M.A., and Belc, N. (2017). Vitamin C and total polyphenol content and antioxidant capacity of fresh and processed fruits of Aronia melanocarpa. Sci. Pap. Ser. B Hort. 61: 433-440.

Cebova, M., Klimentova, J., Janega, P., and Pechanova, O. (2017). Effect of bioactive compound of Aronia melanocarpa on cardiovascula system in experimental hypertension. Oxid. Med. Cell. Longev. 2017 1-8.

Centers for Disease Control and Prevention. About Global Noncommunicable Diseases. https://www.cdc.gov/globalhealth/healthprotection/ncd/about.html. Accessed 2 May, 2020.

Choi, H.S., Kim, J., Kim, S., Deng, H., Lee, D., Kim, C.S., Yun, B., and Lee, D. (2018). Catechol derived from aronia juice through lactic acid bacteria fermentation inhibits breast cancer stem cell formation via modulation Stat3/IL-6 signaling pathway. Mol. Carcinogen. 57(11): 1467-1479.

Czank, C., Cassidy, A., Zhang, Q., Morrison, D.J., Preston, T., Kroon, P.A., Botting, N.P., and Kay, C.D. (2013). Human metabolism and elimination of the anthocyanin, cyanidin-3-glucoside: a 13C-tracer study. Am. J. Clin. Nutr. 97(5): 995-1003.

Daskalova, E., Delchev, S., Peeva, Y., Vladimirova-Kitova, L., Kratchanova, M., Kratchanov, C., and Denev, P. (2015). Antiatherogenic and cardioprotective effects of black chokeberry (Aronia melanocarpa) juice in aging rats. Evid.-Based Complementary Altern. Med. 717439: 1-10.

Daskalova, E., Delchev, S., Topolov, M., Dimitrova, S., Uzunova, Y., Valcheva-Kuzmanova, S., Kratchanova, M., Vladimirova-Kitova, L., and Denev, P. (2019). Aronia melanocarpa (Michx.) Elliot fruit juice reveals neuroprotective effect and improves cognitive and locomotor functions of aged rats. Food Chem. Toxicol. 132: 110674.

de Camargo, A.C., Regitano-d'Arce, M.A.B., Biasoto, A.C.T., and Shahidi, F. (2016). Enzyme-assisted extraction of phenolics from winemaking by-products: Antioxidant potential and inhibition of alpha-glucosidase and lipase activities. Food chemistry. 212: 395-402.

Denev, P.N., Kratchanov, C.G., Ciz, M., Lojek, A., and Kratchanova, M.G. (2012). Bioavailability and antioxidant activity of black chokeberry (Aronia melanocarpa) polyphenols: in vitro and in vivo evidences and 
possible mechanisms of action: a review. Comp. Rev. Food Sci. Food Safety. 11(5): 471-489.

Denev, P., Kratchanova, M., Petrova, I., Klisurova, D., Georgiev, Y., Ognyanov, M., and Yanakieva, I. (2018). Black chokeberry (Aronia melanocarpa (Michx.) Elliot) fruits and functional drinks differ significantly in their chemical composition and antioxidant activity. J. Chem. 9574587: 1-11.

Djuric, M., Brkovic, D.U.Š.K.O., Milosevic, D., Pavlovic, M., and Curcic, S. (2015). Chemical characterization of the fruit of black chokeberry grown on different types of soil. REV CHIM (Bucharest). 66: 178-781.

Duchnowicz, P., Ziobro, A., Rapacka, E., Koter-Michalak, M., and Bukowska, B. (2018). Changes in cholinesterase activity in blood of adolescent with metabolic syndrome after supplementation with extract from Aronia melanocarpa.. BioMed Res. Int. 2018: 1-8.

Dudonné, S., Dubé, P., Anhê, F.F., Pilon, G., Marette, A., Lemire, M., and and Desjardins, Y. (2015). Comprehensive analysis of phenolic compounds and abscisic acid profiles of twelve native Canadian berries. J. Food Comp. Anal. 44: 214-224.

Duffy, V.B., Rawal, S., Park, J., Brand, M.H., Sharafi, M., and Bolling, B.W. (2016). Characterizing and improving the sensory and hedonic responses to polyphenol-rich aronia berry juice. Appetite. 107: 116125.

Dzah, C.S., Duan, Y., Zhang, H., Serwah Boateng, N.A., and Ma, H. (2020). Latest developments in polyphenol recovery and purification from plant by-products: A review. Trends Food Sci. Technol. 99: 375-388.

Famiani, F., Battistelli, A., Moscatello, S., Cruz-Castillo, J.G., and Walker, R.P. (2015). The organic acids that are accumulated in the flesh of fruits: occurrence, metabolism and factors affecting their contents a review. Rev. Chapingo Ser. Hort. XXI(2): 97-128.

Featherstone, S. (2015). Ingredients used in the preparation of canned foods. A Complete Course in Canning and Related Processes. Woodhead Publishing, pp. 147-211.

Festi, D., Schiumerini, R., Eusebi, L.H., Marasco, G., Taddia, M., and Colecchia, A. (2014). Gut microbiota and metabolic syndrome. World J. Gastroenterol. 20(43): 16079.

Grunovaitè, L., Pukalskienè, M., Pukalskas, A., and Venskutonis, P.R. (2016). Fractionation of black chokeberry pomace into functional ingredients using high pressure extraction methods and evaluation of their antioxidant capacity and chemical composition. J. Funct. Foods. 24: 85-96.

Han, Y., Huang, M., Li, L., Cai, X., Gao, Z., Li, F., Rakariyatham, K., Song, M., Fernández Tomé, S., and Xiao, H. (2019). Non-extractable polyphenols from cranberries: potential anti-inflammation and anti-coloncancer agents. Food Funct. 10(12): 7714-7723.

Handeland, M., Grude, N., Torp, T., and Slimestad, R. (2014). Black chokeberry juice (Aronia melanocarpa) reduces incidences of urinary tract infection among nursing home residents in the long term-a pilot study. Nutr. Res. 34(6): 518-525.

Heleno, S.A., Martins, A., Queiroz, M.J.R.P., and Ferreira, I.C.F.R. (2015). Bioactivity of phenolic acids: metabolites versus parent compounds: A review. Food Chem. 173: 501-513.

Hwang, E.-S., and Thi, N.D. (2016). Effects of different growing regions on quality characteristics, bioactive compound contents, and antioxidant activity of aronia (Aronia melanocarpa) in Korea. Prev. Nutr. Food Sci. 21(3): 255-262.

Istas, G., Wood, E., Le Sayec, M., Rawlings, C., Yoon, J., Dandavate, V., Cera, D., Rampelli, S., Costabile, A., Fromentin, E., and Rodriguez-Mateos, A. (2019). Effects of aronia berry (poly)phenols on vascular function and gut microbiota: a double-blind randomized controlled trial in adult men. Am. J. Clin. Nutr. 110(2): 316-329.

Iwashima, T., Kudome, Y., Kishimoto, Y., Saita, E., Tanaka, M., Taguchi, C., Hirakawa, S., Mitani, N., Kondo, K., and lida, K. (2019). Aronia berry extract inhibits TNF- $\alpha$-induced vascular endothelial inflammation through the regulation of STAT3. Food Nutr. Res. 63(0): 1-8.

Jakobek, L., and Seruga, M. (2012). Influence of anthocyanins, flavonols and phenolic acids on the antiradical activity of berries and small fruits. Int. J. Food Prop. 15(1): 122-133.

Jakovljevic, V. (2017). The effects of polyphenol-rich chokeberry juice on redox status in active handball players: Preliminary results from a randomized, double blind controlled study. Atherosclerosis. 263: 169.
Jeong, O., and Kim, H.-S. (2019). Dietary chokeberry and dried jujube fruit attenuates high-fat and high-fructose diet-induced dyslipidemia and insulin resistance via activation of the IRS-1/PI3K/Akt pathway in C57BL/6 J mice. Nutr. Metabol. 16(1): 1-5.

Jiao, X., Wang, Y., Lin, Y., Lang, Y., Li, E., Zhang, X., Zhang, Q., Feng, Y., Meng, $X$. , and Li, B. (2019). Blueberry polyphenols extract as a potential prebiotic with anti-obesity effects on $\mathrm{C} 57 \mathrm{BL} / 6 \mathrm{~J}$ mice by modulating the gut microbiota. J. Nutr. Biochem. 64: 88-100.

Juranović Cindrić, I., Zeiner, M., Mihajlov-Konanov, D., and Stingeder, G. (2017). Inorganic macro- and micronutrients in "superberries" black chokeberries (Aronia melanocarpa) and related teas. Int. J. Environ. Res. Public Health. 14(5): 539.

Jurikova, T., Mlcek, J., Skrovankova, S., Sumczynski, D., Sochor, J., Hlavacova, I., Snopek, L., and Orsavova, J. (2017). Fruits of black chokeberry Aronia melanocarpa in the prevention of chronic diseases. Molecules. 22(6): 944.

Kaşıkcı, M., and Bağdatlıoğlu, N. (2016). Bioavailability of quercetin. Cur. Res. Nutr. Food Sci. J. 4: 46-151.

Kay, C.D., Mazza, G., and Holub, B.J. (2005). Anthocyanins exist in the circulation primarily as metabolites in adult men. J. Nutr. 135(11): 2582-2588.

Kim, D.-H., Lim, H.-W., Kim, S.-H., Lee, J.-M., Chon, J.-W., Song, K.-Y., Bae, D., Kim, J., Kim, H., and Seo, K.-H. (2018). Antibacterial activity of crude Aronia melanocarpa (black chokeberry) extracts against Bacillus cereus, Staphylococcus aureus, Cronobacter sakazakii, and Salmonella Enteritidis in various dairy foods: preliminary study. J. Milk Sci. Biotechnol. 36(3): 155-163.

Kim, J., Lee, K.P., Beak, S., Kang, H.R., Kim, Y.K., and Lim, K. (2019). Effect of black chokeberry on skeletal muscle damage and neuronal cell death. J. Exer. Nutr. Biochem. 23(4): 26-31.

Kitrytė, V., Kraujalienè, V., Šulniūtè, V., Pukalskas, A., and Venskutonis, P.R. (2017). Chokeberry pomace valorization into food ingredients by enzyme-assisted extraction: Process optimization and product characterization. Food Bioprod. Proc. 105: 36-50.

Kulling, S., and Rawel, H. (2008). Chokeberry (Aronia melanocarpa)-a review on the characteristic components and potential health effects. Planta Medica 74(13): 1625-1634.

Lancrajan, I. (2012). Aronia melancarpa, a potential therapeutic agent. Studia Universitatis "Vasile Goldis" Arad. Seria Stiintele Vietii. 22(3): 389.

Lee, H.Y., Weon, J.B., Jung, Y.S., Kim, N.Y., Kim, M.K., and Ma, C.J. (2016). Cognitive-enhancing effect of Aronia melanocarpa extract against memory impairment induced by scopolamine in mice. Evid.-Based Complementary Alt. Med. 6145926: 1-7.

Lee, H.Y., Weon, J.B., Ryu, G., Yang, W.S., Kim, N.Y., Kim, M.K., and Ma, C.J. (2017). Neuroprotective effect of Aronia melanocarpa extract against glutamate-induced oxidative stress in HT22 cells. BMC Complementary Alt. Med. 17: 207.

Lee, K.P., Choi, N.H., Kim, H.-S., Ahn, S., Park, I.-S., and Lee, D.W. (2018). Anti-neuroinflammatory effects of ethanolic extract of black chokeberry (Aronia melanocapa L.) in lipopolysaccharide-stimulated BV2 cells and ICR mice. Nutr. Res. and Pract. 12(1): 13.

Loo, B.-M., Erlund, I., Koli, R., Puukka, P., Hellström, J., Wähälä, K., Mattila, P., and Jula, A. (2016). Consumption of chokeberry (Aronia mitschurinii) products modestly lowered blood pressure and reduced lowgrade inflammation in patients with mildly elevated blood pressure. Nutr. Res. 36(11): 1222-1230.

Luca, S.V., Macovei, I., Bujor, A., Miron, A., Skalicka-Woźniak, K., Aprotosoaie, A.C., and Trifan, A. (2019). Bioactivity of dietary polyphenols: the role of metabolites. Crit. Rev. Food Sci. Nutr. 60(4): 626-659.

Mahoney, J.D., Hau, T.M., Connolly, B.A., and Brand, M.H. Sexual and apomictic seed reproduction in aronia species with different ploidy levels. HortSci 54(4): 642-646.

Markkinen, N., Laaksonen, O., Nahku, R., Kuldjärv, R., and Yang, B. (2019). Impact of lactic acid fermentation on acids, sugars, and phenolic compounds in black chokeberry and sea buckthorn juices. Food Chem. 286: 204-215.

Mayer-Miebach, E., Adamiuk, M., and Behsnilian, D. (2012). Stability of chokeberry bioactive polyphenols during juice processing and stabilization of a polyphenol-rich material from the by-product. Agriculture. 2(3): 244-258. 
Medline Plus. (2019). Minerals. https://medlineplus.gov/minerals.html. Accessed 4 May 2020

Milutinović, M., Veličković Radovanović, R., Šavikin, K., Radenković, S., Arvandi, M., Pešić, M., Kostić, M., Miladinović, B., Branković, S., and Kitić, D. (2019). Chokeberry juice supplementation in type 2 diabetic patients - impact on health status. J. Appl. Biomed. 17(4): 218-224.

Moore, J.X., Chaudhary, N., and Akinyemiju, T. (2017). Metabolic syndrome prevalence by race/ethnicity and sex in the United States, National Health and Nutrition Examination Survey, 1988-2012. Preventing Chronic Disease. 14: 1-5.

Nawirska, A., and Uklańska, C. (2008). Waste products from fruit and vegetable processing as potential sources for food enrichment in dietary fibre. Acta Sci. Pol. Technol. Aliment. 7(2): 35-42.

Neilson, A.P., Goodrich, K.M., and Ferruzzi, M.G. (2017). Nutrition in the Prevention and Treatment of Disease. Bioavailability and Metabolism of Bioactive Compounds From Foods. Academic Press, pp. 301-319.

Neilson, A.P., O'Keefe, S.F., and Bolling, B.W. (2016). High-molecularweight proanthocyanidins in foods: overcoming analytical challenges in pursuit of novel dietary bioactive components. An. Rev. Food Sci. Technol. 7(1): 43-64.

Nour, V., Ionica, M.E., and Trandafir, I. (2015). Bioactive compounds, antioxidant activity and color of hydroponic tomato fruits at different stages of ripening. Not. Bot. Horti Agro. 43(2): 404-412.

Ochmian, I.D., Grajkowski, J., and Smolik, M. (2012). Comparison of some morphological features, quality and chemical content of four cultivars of chokeberry fruits (Aronia melanocarpa). Not. Bot. Horti Agro. 40(1): 253-26

Oprea, E., Manolescu, B.N., Fărcăşanu, I.C., Mladin, P., and Mihele, D. (2014). Studies concerning antioxidant and hypoglycaemic activity of Aronia melanocarpa fruits. Revista Farmacia. 62(2): 254-63.

Oszmiański, J., and Lachowicz, S. (2016). Effect of the production of dried fruits and juice from chokeberry (Aronia melanocarpa L.) on the content and antioxidative activity of bioactive compounds. Molecules. 21(8): 1098

Pavlović, A.N., Brcanović, J.M., Veljković, J.N., Mitić, S.S., Tošić, S.B., Kaličanin, B.M., and and Velimirović, D.S. (2015). Characterization of commercially available products of aronia according to their metal content. Fruits. 70(6): 385-393.

Pei, R., Liu, J., Martin, D.A., Valdez, J.C., Jeffety, J., Barrett-Wilt, G.A., and and Bolling, B.W. (2019). Aronia berry supplementation mitigates inflammation in T cell transfer-induced colitis by decreasing oxidative stress. Nutrients. 11(6): 1316.

Pei, R., Martin, D.A., Valdez, J.C., Liu, J., Kerby, R.L., Rey, F.E., Smyth, J.A. Liu, Z., and Bolling, B.W. (2018). Dietary prevention of colitis by aronia berry is mediated through increased Th17 and Treg. Mol. Nutr. Food Res. 63(5): 1800985

Pérez-Jiménez, J., Neveu, V., Vos, F., and Scalbert, A. (2010). Identification of the 100 richest dietary sources of polyphenols: an application of the Phenol-Explorer database. Eur. J. Clin. Nutr. 64(3): 112-20.

Petrovic, S., Arsic, A., Glibetic, M., Cikiriz, N., Jakovljevic, V., and Vucic, V. (2016). The effects of polyphenol-rich chokeberry juice on fatty acid profiles and lipid peroxidation of active handball players: results from a randomized, double-blind, placebo-controlled study. Can. J. Physiol. Pharmacol. 94(10): 1058-1063.

Pieszka, M., Gogol, P., Pietras, M., and Pieszka, M. (2015). Valuable components of dried pomaces of chokeberry, black currant, strawberry, apple and carrot as a source of natural antioxidants and nutraceuticals in the animal diet. Annals Animal Sci. 15(2): 475-491.

Pojer, E., Mattivi, F., Johnson, D., and Stockley, C.S. (2013). The case for anthocyanin consumption to promote human health: a review: anthocyanins and human health. Comp. Rev. Food Sci. Food Safety. 12(5): 483-508.

Pozderović, A., Popović, K., Pichler, A., and Jakobek, L. (2016). Influence of processing parameters on permeate flow and retention of aroma and phenolic compounds in chokeberry juice concentrated by reverse osmosis. CyTA-J. Food. 14(3): 382-39.

Queipo-Ortuño, M.I., Boto-Ordóñez, M., Murri, M., Gomez-Zumaquero, J.M., Clemente-Rahmani, J., Clark, C., Kord Varkaneh, H., Lakiang, T., Vasanthan, L.T., Onyeche, V., and and Zhang, Y. (2019). The effect of Aronia consumption on lipid profile, blood pressure, and biomarkers of inflammation: A systematic review and meta-analysis of rand- omized controlled trials. Phytother. Res. 33(8): 1981-1990

Rahmani, J., Clark, C., Kord Varkaneh, H., Lakiang, T., Vasanthan, L.T., Onyeche, V., and and Zhang, Y. (2019). The effect of Aronia consumption on lipid profile, blood pressure, and biomarkers of inflammation: A systematic review and meta-analysis of randomized controlled trials. Phytother Res. 33(8): 1981-1990.

Raudsepp, P., Koskar, J., Anton, D., Meremäe, K., Kapp, K., Laurson, P., Bleive, U., Kaldmäe, H., Roasto, M., and Püssa, T. (2019). Antibacterial and antioxidative properties of different parts of garden rhubarb, blackcurrant, chokeberry and blue honeysuckle. J. Sci. Food Agric. 99(5): 2311-2320.

Rauf, A., Imran, M., Abu-Izneid, T., lahtisham-UI-Haq, R.W., Patel, S., Pan, X., Naz, S., Sanches Silva, A., Saeed, F., and Rasul Suleria, H.A. (2019) Proanthocyanidins: a comprehensive review. Biomed. Pharmacother. 116: 108999.

Rodriguez-Castaño, G.P., Dorris, M.R., Liu, X., Bolling, B.W., Acosta-Gonzalez, A., and Rey, F.E. (2019). Bacteroides thetaiotaomicron starch utilization promotes quercetin degradation and butyrate production by Eubacterium ramulus. Front. Microbiol. 10: 1-10.

Rodríguez-Werner, M., Winterhalter, P., and Esatbeyoglu, T. (2019). Phenolic composition, radical scavenging activity and an approach for authentication of Aronia melanocarpa berries, juice, and pomace. J. Food Sci. 84(7): 1791-1798.

Sáenz-Navajas, M.-P., Ferreira, V., Dizy, M., and Fernández-Zurbano, P. (2010). Characterization of taste-active fractions in red wine combining HPLC fractionation, sensory analysis and ultra performance liquid chromatography coupled with mass spectrometry detection. Anal.a Chim. Acta. 673(2): 151-159.

Santhakumar, A.B., Battino, M., and Alvarez-Suarez, J.M. (2018). Dietary polyphenols: Structures, bioavailability and protective effects against atherosclerosis. Food Chem. Toxicol. 113: 49-65.

Schmid, V., Steck, J., Mayer-Miebach, E., Behsnilian, D., Briviba, K., Bunzel, M., Karbstein, H.P., and Azad Emin, M. (2020). Impact of defined thermomechanical treatment on the structure and content of dietary fiber and the stability and bioaccessibility of polyphenols of chokeberry (Aronia melanocarpa) pomace. Food Res. Inter. 134: 109232.

Shahidi, F., Vasudevan Ramakrishnan, V., and Oh, W.Y. (2019). Bioavailability and metabolism of food bioactives and their health effects: a review. J. Food Bioactives 8: 6-41.

Shi, J., Yu, J., Pohorly, J.E., and Kakuda, Y. (2003). Polyphenolics in grape seeds - biochemistry and functionality. J. Med. Food. 6(4): 291-299.

Sidor, A., Drożdżyńska, A., and Gramza-Michałowska, A. (2019). Black chokeberry (Aronia melanocarpa) and its products as potential health-promoting factors - An overview. Trends Food Sci. Technol. 89: 45-60.

Sidor, A., and Gramza-Michałowska, A. (2019). Black chokeberry Aronia melanocarpa L.-a qualitative composition, phenolic profile and antioxidant potential. Molecules. 24(20): 3710.

Skupien, K., and Oszmianki, J. (2008). The effect of mineral fertilization on nutritive value and biological activity of chokeberry fruit. Agric. Food Sci. 16(1): 46-55.

Slavin, J. (2013). Fiber and prebiotics: mechanisms and health benefits. Nutrients. 5(4): 1417-1435.

Šnebergrová, J., Čížková, H., Neradova, E., Kapci, B., Rajchl, A., and Voldřich, M. (2014). Variability of characteristic components of aronia. Czech J. Food Sci. 32(1): 25-30.

Soares, S., García-Estévez, I., Ferrer-Galego, R., Brás, N.F., Brandão, E., Silva, M., Teixeira, N., Fonseca, F., Sousa, S.F., Ferreira-da-Silva, F., Mateus, N., and de Freitas, V. (2018). Study of human salivary prolinerich proteins interaction with food tannins. Food Chem. 243(2018): 175-185

Sójka, M., Kołodziejczyk, K., and Milala, J. (2013). Polyphenolic and basic chemical composition of black chokeberry industrial by-products. Ind. Crops Prod. 51: 77-86.

Sosnowska, D., Podsędek, A., Kucharska, A.Z., Redzynia, M., Opęchowska, M., and Koziołkiewicz, M. (2016). Comparison of in vitro anti-lipase and antioxidant activities, and composition of commercial chokeberry juices. Eur. Food Res. Technol. 242(4): 505-515.

Stevanović, V., Pantović, A., Krga, I., Zeković, M., Šarac, I., Glibetić, M., and Vidović, N. (2019). Aronia juice consumption prior to half-marathon race can acutely affect platelet activation in recreational runners. 
Appl. Physiol. Nutr. Metabol. 45(4): 393-400.

Szopa, A., Ekiert, H., and Muszyńska, B. (2013). Accumulation of hydroxybenzoic acids and other biologically active phenolic acids in shoot and callus cultures of Aronia melanocarpa (Michx.) Elliott (black chokeberry). Plant Cell Tissue Organ Culture. 113(2): 323-329.

Taheri, R., Connolly, B.A., Brand, M.H., and Bolling, B.W. (2013). Underutilized chokeberry (Aronia melanocarpa, Aronia arbutifolia, Aronia prunifolia) accessions are rich sources of anthocyanins, flavonoids, hydroxycinnamic acids, and proanthocyanidins. J. Agric. Food Chem. 61(36): 8581-8588.

Teleszko, M., and Wojdyło, A. (2015). Comparison of phenolic compounds and antioxidant potential between selected edible fruits and their leaves. J. Funct. Foods. 14: 736-746.

Thi, N., and Hwang, E.-S. (2018). Effects of black chokeberry extracts on metastasis and cell-cycle arrest in SK-Hep1 human liver cancer cell line. Asian Pac. J. Trop. Biomed. 8(6): 285.

Tian, Y., Liimatainen, J., Alanne, A.L., Lindstedt, A., Liu, P., Sinkkonen, J., and and Yang, B. (2017). Phenolic compounds extracted by acidic aqueous ethanol from berries and leaves of different berry plants. Food Chem. 220: 266-281.

Tomić, M., Ignjatović, Đ., Tovilović-Kovačević, G., Krstić-Milošević, D., Ranković, S., Popović, T., and Glibetić, M. (2016). Reduction of anxiety-like and depression-like behaviors in rats after one month of drinking Aronia melanocarpa berry juice. Food Funct. 7(7): 3111-3120.

Ungaro, R., Colombel, J.-F., Lissoos, T., and Peyrin-Biroulet, L. (2019). A treat-to-target update in Ulcerative Colitis. Am. J. Gastroenterol. 114(6): 874-883.

US Food and Drug Administration. Code of Federal Regulations Title 21. https://www.accessdata.fda.gov/scripts/cdrh/cfdocs/cfcfr/CFRSearch.cfm?fr=101.9\&SearchTerm=nutrition\%20label. Accessed 29 Aug 2020.

Valcheva-Kuzmanova, S., Eftimov, M., Denev, P., Krachanova, M., and Belcheva, A. (2013). Effect of Aronia melanocarpa fruit juice on alcohol-induced depressive-like behavior in rats. Scripta Sci. Med. 45: 7-13.

Valcheva-Kuzmanova, S., Kuzmanov, A., Kuzmanova, V., and Tzaneva, M. (2018). Aronia melanocarpa fruit juice ameliorates the symptoms of inflammatory bowel disease in TNBS-incuced colitis in rats. Food Chem. Toxicol. 113: 33-39.

Valdez, J.C., and Bolling, B.W. (2019). Anthocyanins and intestinal barrier function: a review. J. Food Bioactives. 5: 18-30.

Valdez, J.C., Cho, J., and Bolling, B.W. (2020). Aronia berry inhibits disruption of Caco-2 intestinal barrier function. Arch. Biochem. Biophys. 668: 108409.

Varela, C.E., Fromentin, E., Roller, M., Villarreal, F., and Ramirez-Sanchez, I. (2015). Effects of a natural extract of Aronia melanocarpa berry on endothelial cell nitric oxide production. J. Food Biochem. 40(4): 404-410.

Vázquez-Espinosa, M., González-de-Peredo, V.A., Espada-Bellido, E., Ferreiro-González, M., Toledo-Domínguez, J.J., Carrera, C., and and $F$ Barbero, G. (2019). Ultrasound-Assisted Extraction of Two Types of Antioxidant Compounds (TPC and TA) from Black Chokeberry (Aronia melanocarpa L.): Optimization of the Individual and Simultaneous Extraction Methods. Agronomy. 9(8): 456.

Veberic, R., Slatnar, A., Bizjak, J., Stampar, F., and Mikulic-Petkovsek, M. (2015). Anthocyanin composition of different wild and cultivated berry species. LWT Food Sci. Technol. 60(1): 509-517.
Wangensteen, H., Bräunlich, M., Nikolic, V., Malterud, K.E., Slimestad, R., and Barsett, H. (2014). Anthocyanins, proanthocyanidins and total phenolics in four cultivars of aronia: Antioxidant and enzyme inhibitory effects. J. Funct. Foods. 7: 746-752.

Wathon, M.H., Beaumont, N., Benohoud, M., Blackburn, R.S., and Rayner, C.M. (2019). Extraction of anthocyanins from Aronia melanocarpa skin waste as a sustainable source of natural colorants. Color. Technol. 135(1): 5-16.

Wiczkowski, W., Romaszko, E., and Piskula, M.K. (2010). Bioavailability of cyanidin glycosides from natural chokeberry (Aronia melanocarpa) juice with dietary-relevant dose of anthocyanins in humans. J. Agric. Food Chem. 58(23): 12130-12136.

Wilkowska, A., Ambroziak, W., Adamiec, J., and Czyżowska, A. (2017). Preservation of antioxidant activity and polyphenols in chokeberry juice and wine with the use of microencapsulation. J. Food Proc. Pres. 41(3): 12924.

Williamson, G., and Clifford, M.N. (2017). Role of the small intestine, colon and microbiota in determining the metabolic fate of polyphenols. Biochem. Pharmacol. 139: 24-39.

Wu, T., Grootaert, C., Pitart, J., Vidovic, N.K., Kamiloglu, S., Possemiers, S., Glibetic, M., Smagghe, G., Raes, K., Van de Wiele, T., and Van Camp, J. (2018). Aronia (Aronia melanocarpa) polyphenols modulate the microbial community in a simulator of the human intestinal microbial ecosystem (SHIME) and decrease secretion of proinflammatory markers in a Caco-2/endothelial cell coculture model. Mol. Nutr. Food Res. 62(22): 1800607.

Xie, L., Lee, S.G., Vance, T.M., Wang, Y., Kim, B., Lee, J.Y., Chun, O.K., and Bolling, B.W. (2016). Bioavailability of anthocyanins and colonic polyphenol metabolites following consumption of aronia berry extract. Food Chem. 211: 860-868.

Xie, L., Vance, T., Kim, B., Lee, S.G., Caceres, C., Wang, Y., Hubert, P.A., Lee, J.-Y., Chun, O.K., and Bolling, B.W. (2017). Aronia berry polyphenol consumption reduces plasma total and low-density lipoprotein cholesterol in former smokers without lowering biomarkers of inflammation and oxidative stress: a randomized controlled trial. Nutr. Res. 37: 67-77.

Yamane, T., Kozuka, M., Imai, M., Yamamoto, Y., Ohkubo, I., Sakamoto, T., Nakagaki, T., and Nakano, Y. (2017). Reduction of blood pressure by aronia berries through inhibition of angiotensin-converting enzyme activity in the spontaneously hypertensive rat kidney. Funct. Foods Health Dis. 7(4): 280-290.

Yamane, T., Kozuka, M., Konda, D., Nakano, Y., Nakagaki, T., Ohkubo, I., and Ariga, H. (2016). Improvement of blood glucose levels and obesity in mice given aronia juice by inhibition of dipeptidyl peptidase IV and a-glucosidase. J. Nutr. Biochem. 31: 106-112.

Yamane, T., Kozuka, M., Wada-Yoneta, M., Sakamoto, T., Nakagaki, T., Nakano, Y., and Ohkubo, I. (2017). Aronia juice suppresses the elevation of postprandial blood glucose levels in adult healthy Japanese. Clin. Nutr. Exper. 12: 20-26.

Yamane, T., Kozuka, M., Yamamoto, Y., Nakano, Y., Nakagaki, T., Ohkubo, I., and Ariga, H. (2016). Effectiveness of aronia berries for reduction of mild fibrosis and gene expression analysis in livers from mice fed a high-fat diet with aronia berries. Funct. Foods Health Dis. 6(3): 144-157.

Zlatanov, M.D. (1999). Lipid composition of Bulgarian chokeberry, black currant and rose hip seed oils. J. Sci. Food Agric. 79(12): 1620-1624. 